\title{
Oral HRAS Mutation in Orofacial Nevus Sebaceous Syndrome (Schimmelpenning-Feuerstein-Mims-Syndrome): A Case Report With a Literature Survey
}

\author{
REINHARD E. FRIEDRICH ${ }^{1}$, MARTIN GOSAU ${ }^{1}$, ANDREAS M. LUEBKE ${ }^{2}$, CHRISTIAN HAGEL ${ }^{3}$, \\ FELIX K. KOHLRUSCH ${ }^{1}$, MICHAEL HAHN ${ }^{4}$, SIMON VON KROGE ${ }^{4}$, JAN HAHN ${ }^{5,6}$, \\ ILSE WIELAND $^{7}$ and MARTIN ZENKER ${ }^{7}$ \\ ${ }^{1}$ Department of Oral and Craniomaxillofacial Surgery, Eppendorf University Hospital, \\ University of Hamburg, Hamburg, Germany; \\ ${ }^{2}$ Institute of Pathology, Eppendorf University Hospital, University of Hamburg, Hamburg, Germany; \\ ${ }^{3}$ Institute of Neuropathology, Eppendorf University Hospital, University of Hamburg, Hamburg, Germany; \\ ${ }^{4}$ Institute of Osteology and Biomechanics, Eppendorf University Hospital, \\ University of Hamburg, Hamburg, Germany; \\ ${ }^{5}$ Max Planck Institute for the Structure and Dynamics of Matter (MPSD), \\ Center for Free Electron Laser Science (CFEL), Hamburg, Germany; \\ ${ }^{6}$ Section Mass Spectrometry and Proteomics, Institute of Clinical Chemistry and Laboratory Medicine, \\ University Medical Center Hamburg-Eppendorf, Hamburg, Germany; \\ ${ }^{7}$ Institute of Human Genetics, Otto-von-Guericke University, Magdeburg, Germany
}

\begin{abstract}
Background/Aim: The aim of this study was to present the long-term course of a patient with nevus sebaceous syndrome (NSS). Recent genetic studies place the syndrome in the emerging group of so-called RASopathies. The focus of the report is on surgical treatment and morphological and genetic findings of the face and oral cavity. Case Report: A female patient was treated for congenital alterations of facial skin and oral тисова. The oral lesions were removed repeatedly. Eruption of teeth on the lesion sites was made easier by the measures taken. However, after repeated ablation of the affected gingiva, the periodontal papillomatous epithelium redifferentiated into the same reddish, conspicuous, hyperplastic epithelium. The teeth in the affected region showed noticeable changes in position, surface, and shape. A HRAS mutation was detected only in the regions of altered oral epithelia and
\end{abstract}

This article is freely accessible online.

Correspondence to: Professor R.E. Friedrich, MD, DMD, Ph.D., FEBOMFS, Department of Oral and Craniomaxillofacial Surgery, Eppendorf University Hospital, University of Hamburg, Martinist. 52, D-2046 Hamburg, Germany. Tel: +49 40741053259, e-mail: rfriedrich@uke.de

Key Words: Nevus sebaceous syndrome, RAS mutation, oral papillomatosis, dysmorphic teeth, neural crest, polydactyly, optical coherence tomography, micro-CT. not in adjacent soft tissues. Conclusion: Reports on NSS rarely address oral manifestations. The recorded alterations of oral soft and hard tissues in NSS indicate a topographical relationship between the development of oral mucosa and teeth as well as the long-lasting impact of a sporadic mutation on organ development at this site.

Epidermal nevi (EN) are mosaic cutaneous developmental disorders (1-6). EN are differentiated according to the predominant epithelial cell types (7). The terminology of nevi refers to the histological components of the lesion (8). If extracutaneous findings are noted in addition to $\mathrm{EN}$ in an individual, this constellation is referred to as epidermal nevus syndrome (ENS) (1-6, 9-12). Some authors have used the term 'ENS' to describe a distinct entity, in particular (linear) nevus sebaceous syndrome (NSS) (synonymous: SchimmelpenningFeuerstein-Mims (SFM) syndrome, Naevus sebaceous Jadassohn (syndrome), Solomon syndrome, and further terms) $(1-6,8,10)$. Other authors subsumed a group of cutaneous diseases characterized by nevi and extracutaneous findings under the term 'ENS' $(1,10)$. Currently, the term 'ENS' is mostly used as an umbrella designation for several syndromes describing diseases with a potentially large variety of physical findings that frequently first attract attention through noticeable alterations in superficial skin layers, in particular nevi $(3-5,8)$. With this broad sense, ENS also includes nevi that have adnexal differentiation (10). 

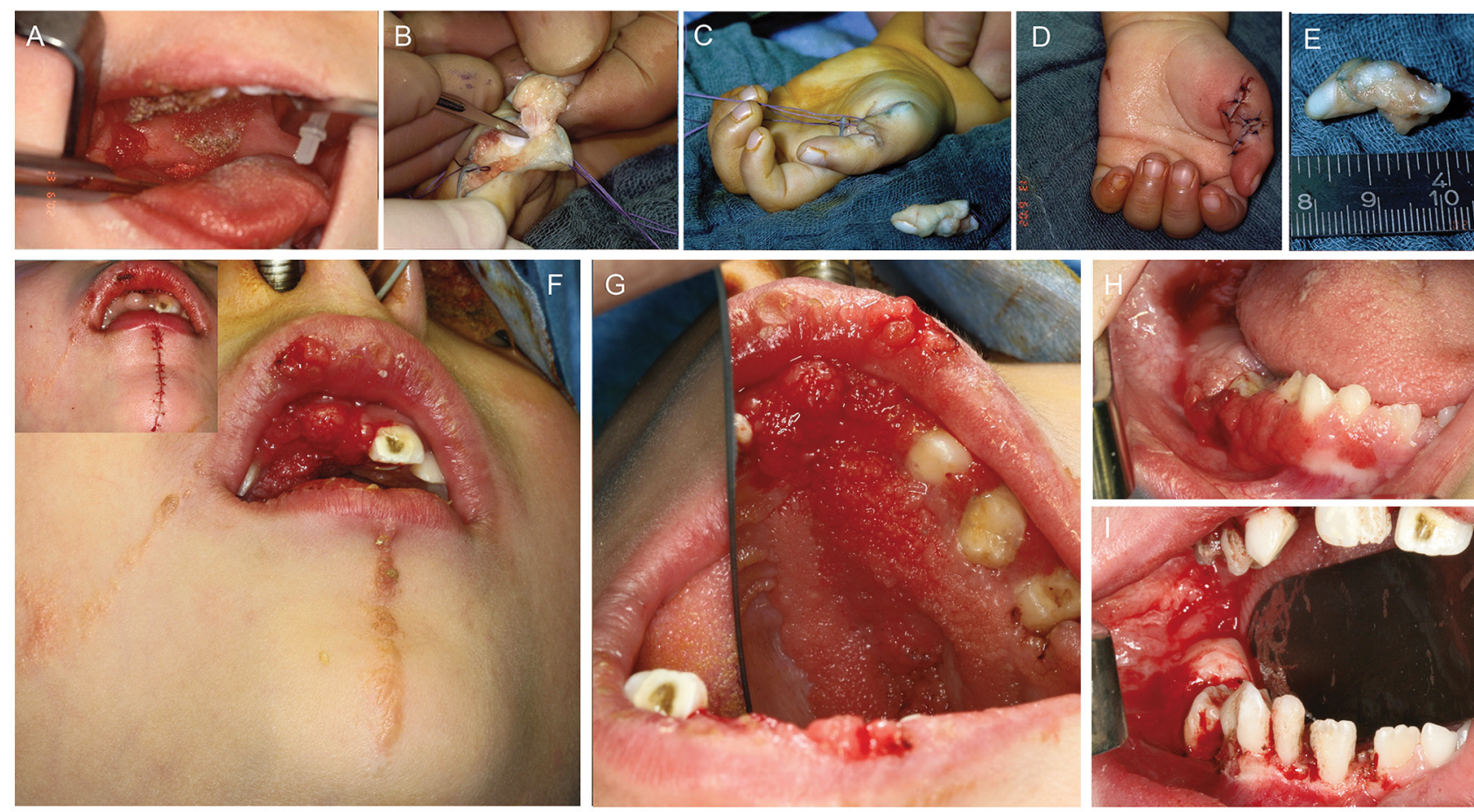

Figure 1. Treatment of patient with nevus sebaceous syndrome in early childhood. (A) $\mathrm{CO}_{2}$ laser ablation of palatal lesion at the age of one year. The lesion that has not yet been treated is visible on the right intermaxillary. (B) Disarticulation of the excess left thumb with preparation $(C)$ and closure with a Z-plasty $(D)$. (E) The amputate is approx. $2 \mathrm{~cm}$ long. $(F)$ Treatment of the patient for the reduction of oral papillomatous hyperplastic mucosa at the age of six years. The illustration shows the linear, slightly raised and hyperpigmented skin changes. The lips are also focally affected by the hyperplasia but have no pigment changes compared to the normal lip skin. The left upper incisor, which is focally discolored on the labial surface, is surrounded by an erythematous mucous membrane in a semicircle from the midline. The two right upper incisors are not emerged. Instead, this gap in the row of teeth covers a confluent papillomatous mucous membrane. (Insert: situs after excision of the chin lesion and removal of the lip papilloma). $(G)$ The maxillary mucosal alteration involves the entire right part of the upper jaw, respects the median sagittal plane as the limit of spread and has prevented the development of palatal rugae. The crowns of deciduous teeth are partially overgrown by papillomatous mucous membrane and have structural anomalies. Note the abnormal spacing of the teeth shown. (H-I) Recurrent mucosal hyperplasia eight months following previous surgery. Photographs depict affected region limited to the mandibular alveolar process and retromolar area before ( $H)$ and after (I) ablation. Note spontaneous emergence of right central incisor after mucosa ablation five years before (I).

EN accounts for about half of all nevi (5). The distinction between keratinocytic and organoid nevi is an essential diagnostic tool in recognizing the very variable phenotypes both in cases with sporadic nevi and nevi associated with syndromes $(1,8,13)$. However, recent genetic investigations show the same mutations of rat sarcoma homolog (RAS) genes in EN both in keratinocytic and organoid lesions and in sporadic and syndrome-associated lesions (14-22). Obviously, the phenotype of many lesions can be traced back to the timing of somatic mutations in certain cells and genes during ontogenesis $(8,17,19,23)$. The diseases are not considered to be inheritable because it is believed that germline mutations in the causative genes lead to non-viable organisms (24). In summary, accumulating molecular genetic research results support current concepts of a common genetic basis concerning different phenotypes of sporadic and syndromic skin disorders characterized by nevi $(6,10,14,15,19)$.
NSS is a frequent ENS (3-5) and rated among the phacomatoses not classified elsewhere (International Classification of Diseases, Version 10 (ICD-10): Q85.8). Craniofacial findings are a characteristic of NSS $(18,25)$. However, oral findings in NSS are rarely reported $(19,26$, 27). This report describes some unusual features in a NSS patient noted during a long observation period with special consideration of orofacial findings.

\section{Case Report}

Infancy. Face and neck. According to the mother's statement, the child was born with facial skin alterations not further specified. On the first presentation of the 11-month-old patient in the Oral and Craniomaxillofacial Surgery Outpatient Clinic, Eppendorf University Hospital, multiple skin-colored, lineshaped, slightly raised efflorescences were documented in 

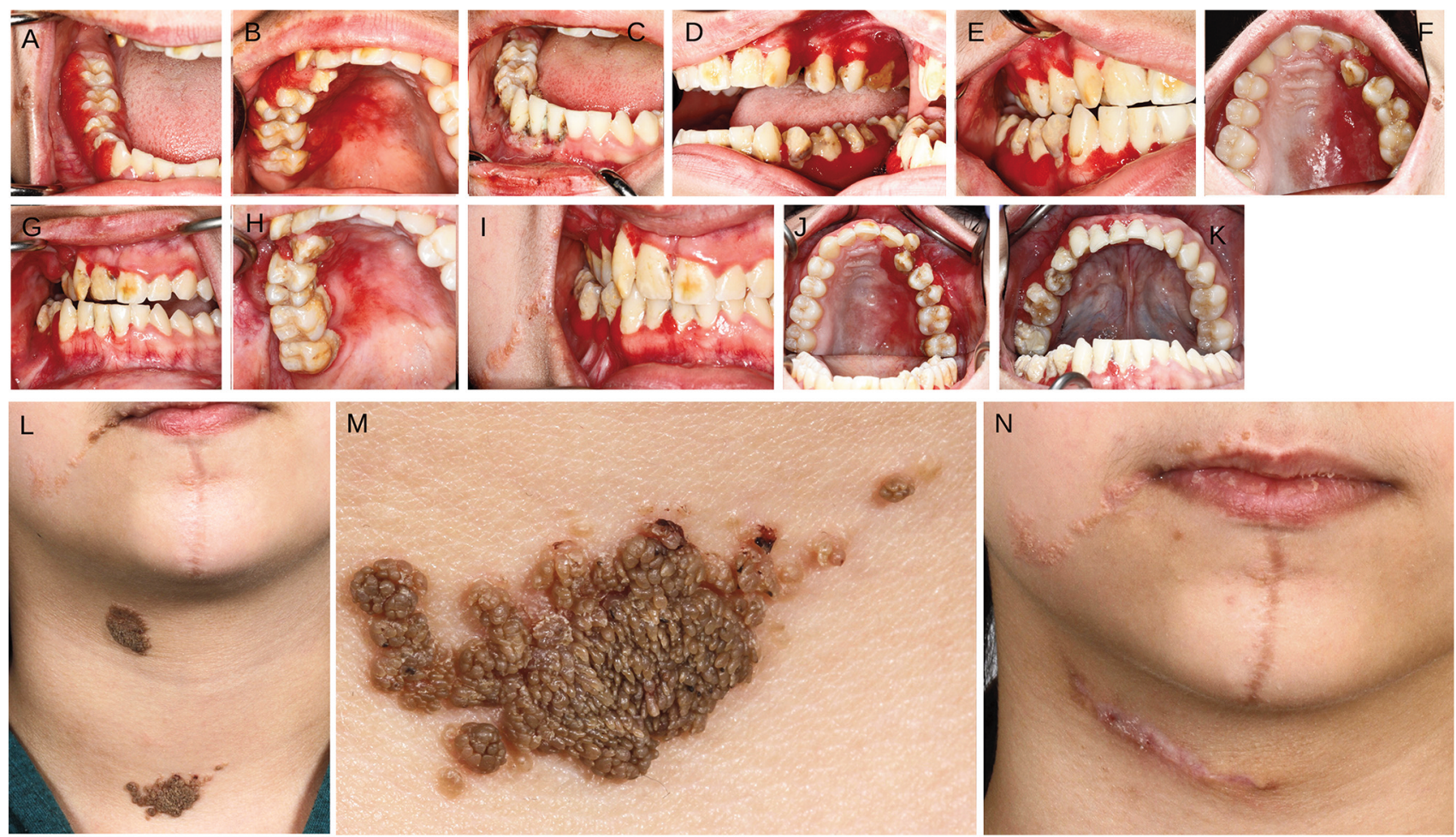

Figure 2. Treatment of the patient with epidermal nevus sebaceous syndrome in adolescence. Erythematous mucosal hyperplasia of the right alveolar process of the mandible $(A)$ and the maxilla $(B)$ of the 15-year-old patient. In the maxilla, residues of the hyperplasia extend partially to the midline of the palate. There is a noticeable, narrow tip on the occlusal contact surface of the palatal emerged right upper canine (B). (C) Mandible situs one week after the hyperplastic mucosa has been removed. (D-F) Recurrence of the hyperplasia six weeks after the operation (E: mirror image photo). (G-H) Regenerated mucous membrane after renewed ablation at the age of 19 years. Seven months later, the recurrence is evident (I-K). The palatal rugae have remained unilaterally developed. (L) Sebacic nevi in the extension of the right oral cavity and on the neck. M) A nevus of the neck in detail. (N) Detailed view of the lower face and neck shortly after removing the nevi.

perioral areas, lips, chin, and anterior neck, all confined to the right side of the body. A linear efflorescence was very noticeable running vertically in the midline from the lower lip to the tip of the chin. The course of the lines of the facial skin corresponded to the lines described by Blaschko (28). The patient family history has no evidence of genetic diseases.

Oral cavity soft tissue lesions, facial skin lesions, and polydactyly treatment. Oral inspection revealed erythematouspapillomatous alterations of the mucosa and gingiva of the following anatomical units: hard palate (with transition to soft palate) and alveolar ridge of the maxilla and mandible. All integumental findings were right-sided. Only 2 lower central deciduous incisors of normal shape and colour had emerged, so no further findings could be made on the dental status. Hexadactyly of the left hand with a complete second thumb was noticeable. The additional digit had fully developed two terminal bone segments.

At the age of 18 months, the altered oral mucosa was removed with the $\mathrm{CO}_{2}$ laser (Figure 1A). In the same surgical setting, the surplus, hypoplastic, radial digit of the left hand was disarticulated and removed without complications (Figure 1B-E).

At the age of 6 years, the oral hyperplasia of the mucous membrane was removed again because the child frequently had bled from recurrent mucosal injuries while eating (Figure 1F-I). Furthermore, the eruption of teeth on the affected side of the body was delayed, deciduous lower right second molar tooth in the crossbite position and lower right first molar in non-occlusion. Therefore, the removal of the tissue was intended also to facilitate tooth eruption. Wound healing took place through secondary intention. Since the oral mucosal hyperplasia rapidly re-established, the procedure was repeated three months later. After permanent removal of the occlusal mucosal proliferation, eruption of retained teeth soon gained height of the occlusal plane.

Adolescence and early adulthood. The child was examined again on an outpatient basis at the age of 13 years to assess and treat the recurrent oral mucosal lesions. Histological and 


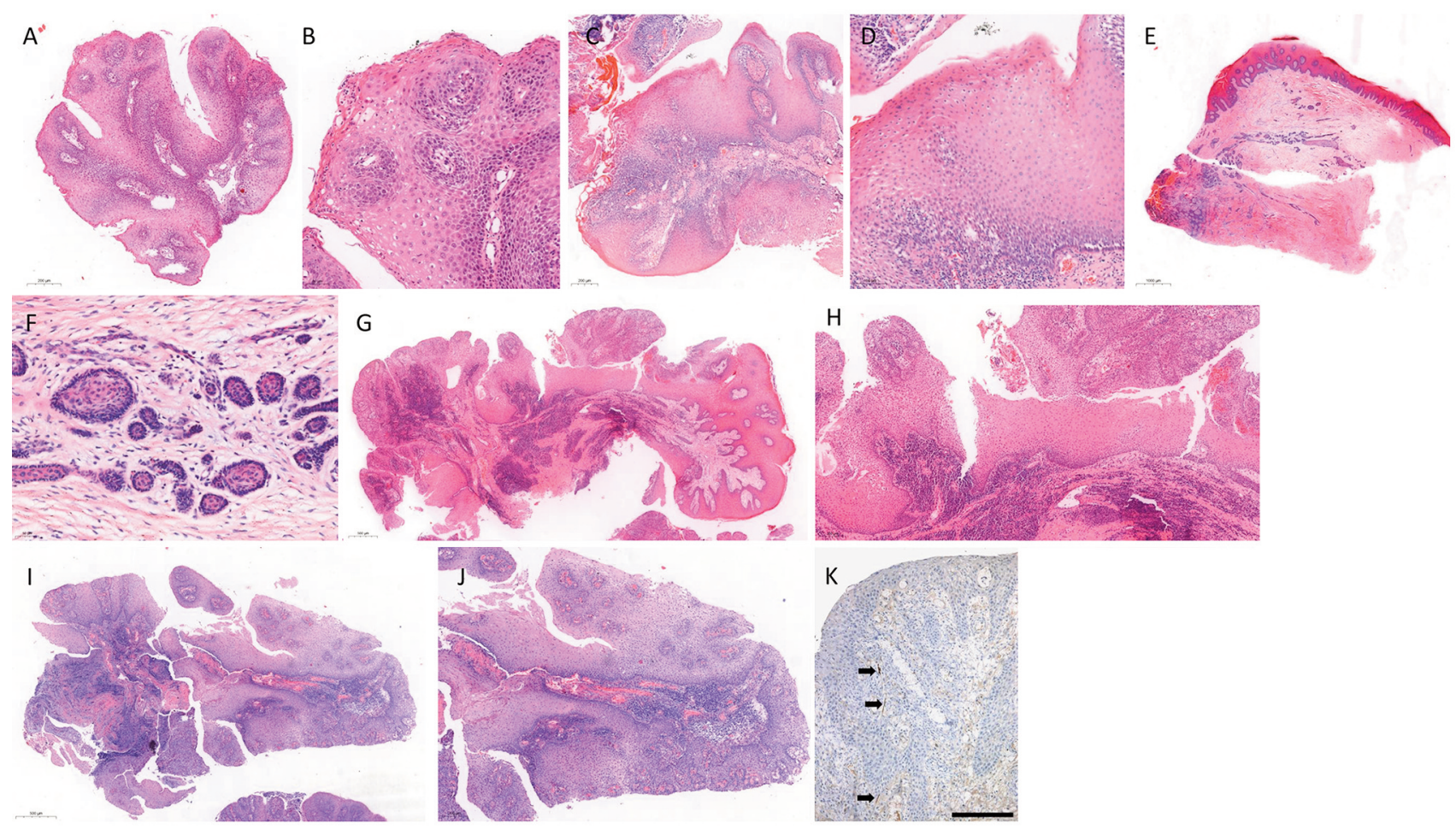

Figure 3. Figures A to J show the course of histological findings over an interval of almost 20 years. The explanations to the figures are given in the text. Hematoxylin-eosin stain. Figure K: Immunohistochemical identification of neurofilament in the oral lesion. A total of 38 neurofilamentpositive nerve fibers, some arranged in small groups, were found in the sample, which has an area of 2 square centimeters (scale bar=200 $\mu m$, arrows point to the nerve fibers).

virological examinations initially gave rise to the suspicion of an HPV-associated venereal disease. Further examination of the patient excluded condyloma acuminata and venereal disease, so a coincidental contamination of the oral tissue with HPV was assumed. At the age of 15 and 19 years, slightly vulnerable, deep periodontal pocket-forming lesions were again removed (Figure 2A-K). The lateral incisor, canine, and premolars of the right side of maxilla were already palpably loosened by the loss of alveolar bone. Only the teeth affected by the soft tissue lesions were significantly covered by calculus indicating severely hampered oral hygiene in the affected oral fields. At the same time of oral mucosa reduction were excised a small drop-like protrusion of the columella, a linear, slightly, and irregularly raised tumor-like skin alterations in the right corner of the mouth and very noticeable, darkly pigmented, raised nevi on the right side of the neck and the jugulum (Figure 2L-N). The anterior neck scars were excised 10 months later and reduced in size. During the ablation of the papillomatous mucous membrane of the lower jaw, the retained right wisdom tooth was removed at the age of 19 years. The wound healing of the osteotomized bone region was uncomplicated. During the observation period of currently 20 years, the patient has not developed pathological neurological or ophthalmological findings.
Histology. The oral specimens obtained during the first surgical procedure of the infant, show in histological examination of fragmentary oral specimen, a papillomatousexophytic proliferating squamous epithelium with koilocytosis and slight inflammatory infiltrates (Figure 3A, B). The histological examination of the accessory thumb, which was $2.6 \mathrm{~cm}$ long and $1 \mathrm{~cm}$ in diameter, revealed the characteristic features of a supernumerary digit with a normal architecture of the skin, soft tissue, and bone with proper ossification. Also, hyaline cartilage tissue with a transition to bone tissue was seen. The specimen's skin showed regularly differentiated squamous epithelium. The histological findings of both oral interventions at the age of 6 years (Figure 3C, D) corresponded to those of the initial examination at the age of 11 months. The histological findings of the simultaneously excised chin scar described a hypertrophic, fibrotic connective tissue without any remnants of skin appendages. The oral specimen of the 13-year-old female was nodular hyperplastic gingiva with hyper- and parakeratosis as well as acanthosis associated with tumorlike proliferations arising from rests of the dental lamina (Figure 3E). The specimen showed squamous metaplasia (Figure 3F) without inflammation, but no mucosal papilloma. In contrast, when the 16-year-old patient again 


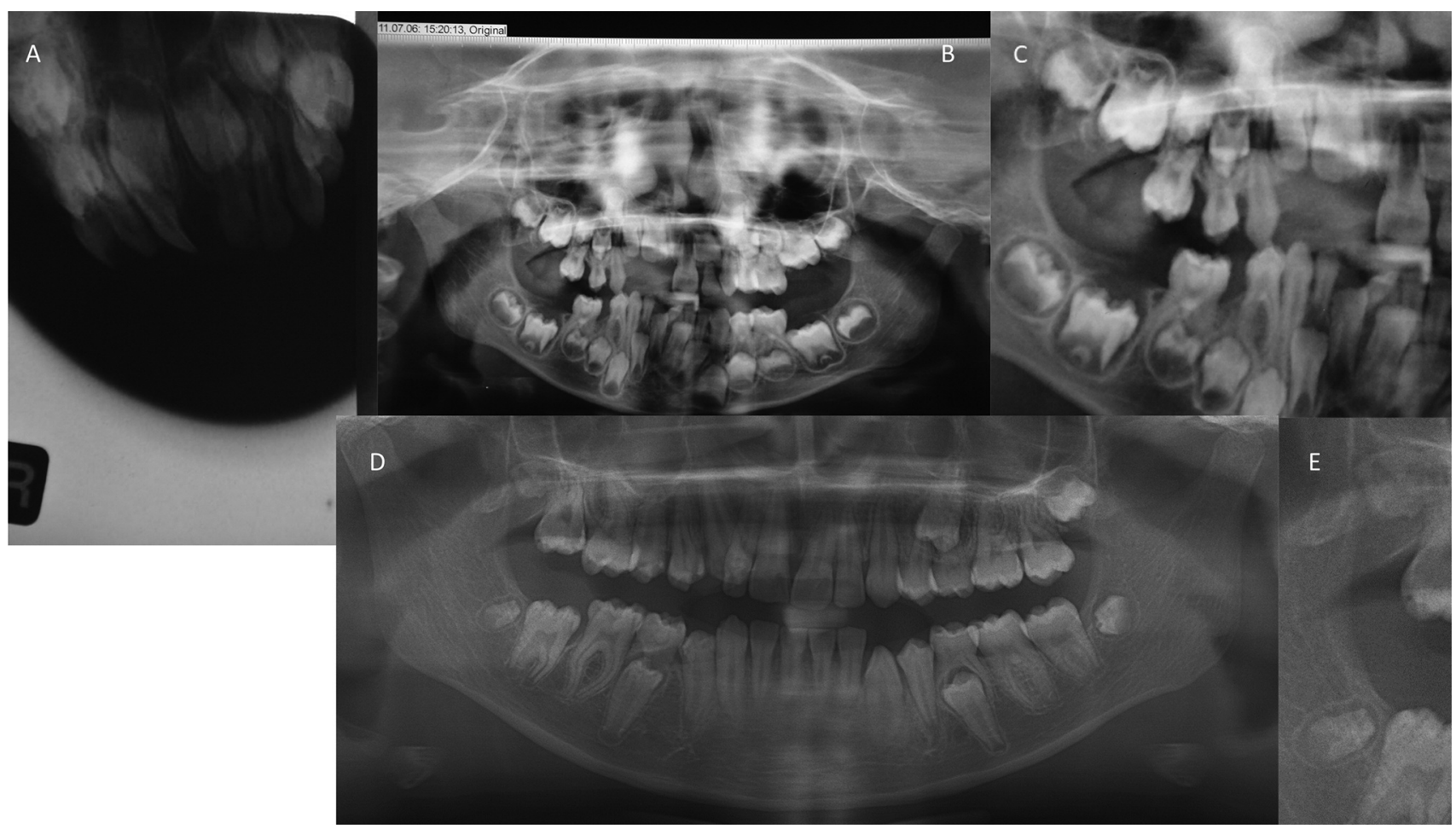

Figure 4. Radiological representation of the dental and jaw findings of the patient with nevus sebaceous syndrome. (A) Occlusal record of the upper jaw. Complete deciduous teeth on the affected side of the jaw. The X-ray records deep vertical furrows in the enamel region of the deciduous molars. The permanent incisors are bilateral and at the same stage of crown development. (B) Panoramic view (PV) of the five-and-a-half-year-old child. Except for the wisdom teeth, all permanent teeth are present. The right upper incisors are retained, their predecessors are missing. The deciduous molars and canines on the right side appear somewhat smaller than those on the opposite side on the not quite symmetrically aligned skull radiograph. The formation of an anatomical equator, especially the first deciduous molars, seems to be reduced. Deep indentation of the occlusal enamel surface of the lower right first molar. (C) is detail of (A). (D) PV of the 13-year-old patient. Complete rows of teeth in both jaws with ageappropriate root development. The wisdom teeth are in place (crown stage). On the left side, both wisdom teeth show a clear, occlusal side increased radiopacity indicating enamel formation. In contrast, the wisdom teeth on the right side appear radio-translucent and hardly distinguishable from the surrounding bone in terms of density. The oval shaped right lower wisdom tooth has a tapered crown region. $(E)$ is detail from $(D)$ to illustrate the radiological morphology of the right wisdom teeth.

had a reduction for mucosa hyperplasia, verrucous acanthosis and papillomatosis of the mucous membrane were noticeable (Figure 3G, H). For this purpose, the specimen was further processed to clarify the potential association of the lesion with human papilloma virus (HPV). HPV6 DNA was detected in oral lesions utilizing the polymerase chain reaction (PCR). At the age of 19 years, the oral lesions showed similar histological characteristics like three years before: Verrucous acanthosis, papillomatosis, and strong chronic inflammation (Figure 3I, J). Despite the koilocytic aspect, the lesions were now HPV-negative (consensus primer MY09/MY11). A remarkable feature is the increasing dominance of the inflammatory changes that reached their maximum in the most recent specimens. Additional excisions revealed trichilemmoma of the columella and verruca filiformis with epidermal nevus in the right corner of the mouth, matching a nevus sebaceous. The tumors of the anterior neck were also sebaceous nevi. Apart from fibrosed scar tissue, there were no organoid structures in the excised scars from the neck in the histological examination of the specimen. The peripheral nerve fibers within the oral lesions are inconspicuously structured and express neurofilament (Figure 3K).

Radiology of jaws and teeth. A bite image of the upper jaw of the two year and seven months aged child shows the fully developed crowns of the permanent central incisors at the same level within the bone. This X-ray also shows the patient's complete maxillary anterior deciduous dentition (Figure 4A). The OPG, made at the age of five and a half, shows symmetrical tooth development in the lower jaw (Figure 4B). In the upper jaw, the developmental stages of the permanent teeth were also symmetrical. However, both incisors on the right side have eroded the covering bone but are completely retained (Figure $4 \mathrm{C}$ ). The X-ray findings correlate with the oral mucosal findings at the same time, 

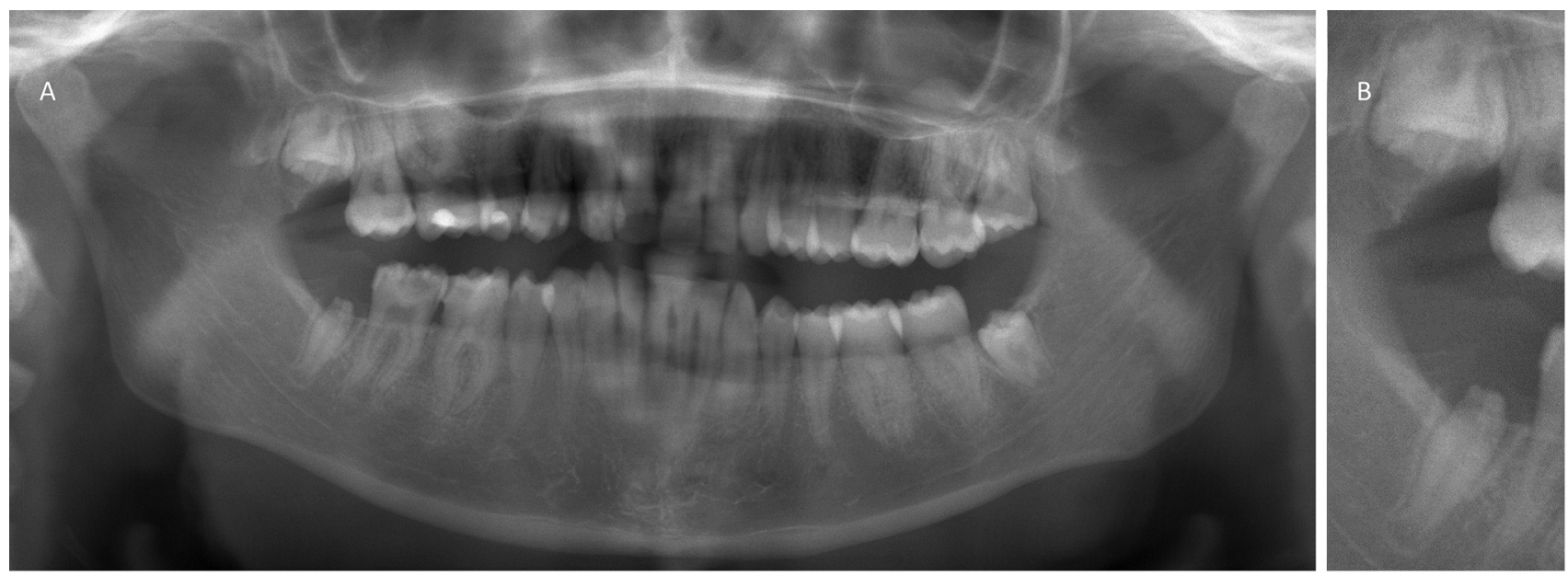

Figure 5. Panoramic view (PV) of the 18-year-old patient. (A) Complete, occasionally preserved permanent dentition. The wisdom teeth are further developed in the root area. The left upper wisdom tooth has emerged, and the converging roots have canal walls aligned parallel to one another in the apical area on the pulp side. The lower left wisdom tooth has open apices, and the root growth is not yet complete. The roots of the lower left wisdom tooth are developed shorter than the roots of the right one. In contrast to the unaffected side, the right upper molar is hardly developed beyond the crown stage. The radiopacity of the retained tooth has increased significantly in the crown area. The wisdom tooth has developed a relatively long root in the lower jaw. However, the tooth crown is rudimentary. In a side comparison of the emerged teeth, the lower radiopacity of the crowns of the lower right molars in the occlusal area is noticeable (deep caries on tooth 47). (B) Detail of PV shown in (A) to illustrate the dysmorphic right wisdom teeth.
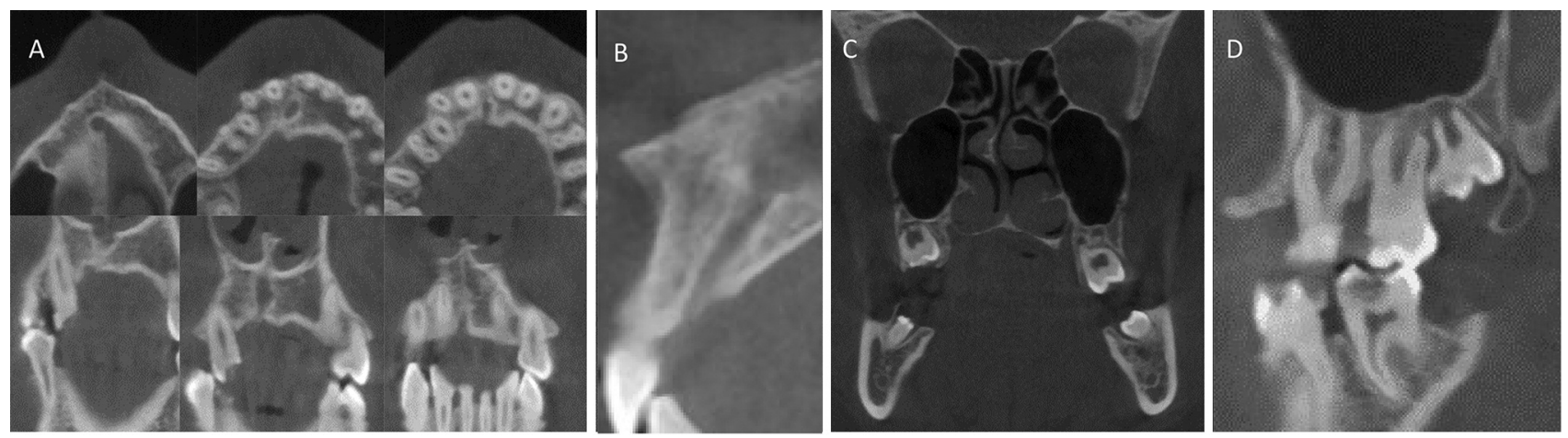

Figure 6. Cone beam computed tomography (CBCT) of jaws in a patient with nevus sebaceous syndrome (cropped images). (A) A series of six cross sectional images depicting anterior maxilla in axial (upper row) and coronal plane (lower row). The nasopalatine canal is lateralized to the affected side. The canal runs distal to the central incisors and close to the root of the right central incisor. The lower row shows the straight course of the canal to the right of the median sagittal plane. (B) The shape of the canal is inconspicuous in the sagittal section. (C) The coronal sectional image of the skull in the plane of the wisdom teeth shows a higher position of the right side of the palate. In this area, the mucosal alteration on the right side was already evident in early childhood. In contrast to the panoramic views, CBCT shows a - albeit interrupted - radiopaque crown layer (enamel) of the lower right wisdom tooth. (D) The section in the sagittal plane of the right side of the jaw shows the dysmorphic right upper third molar, (deep occlusal caries on tooth 47).

which show a dense, hypertrophic mucosa that completely covers the alveolar process of the retained right maxillary incisors (Figure 1F, G).

Another OPG is not carried out until seven years later (Figure 4D, E). The X-ray shows a complete dentition. After surgical reduction of the oral papilloma in the maxillary anterior region, both anterior teeth have erupted and have developed a complete root. Crowns of all 4 wisdom teeth are present in the expected regions. None of the wisdom teeth has reached the initial root stage. On the right side, the lower wisdom tooth looks hypoplastic and could be a small odontoma (Figure 4E). The right upper wisdom tooth appears significantly hypomineralized compared to the left (Figure 4D). 

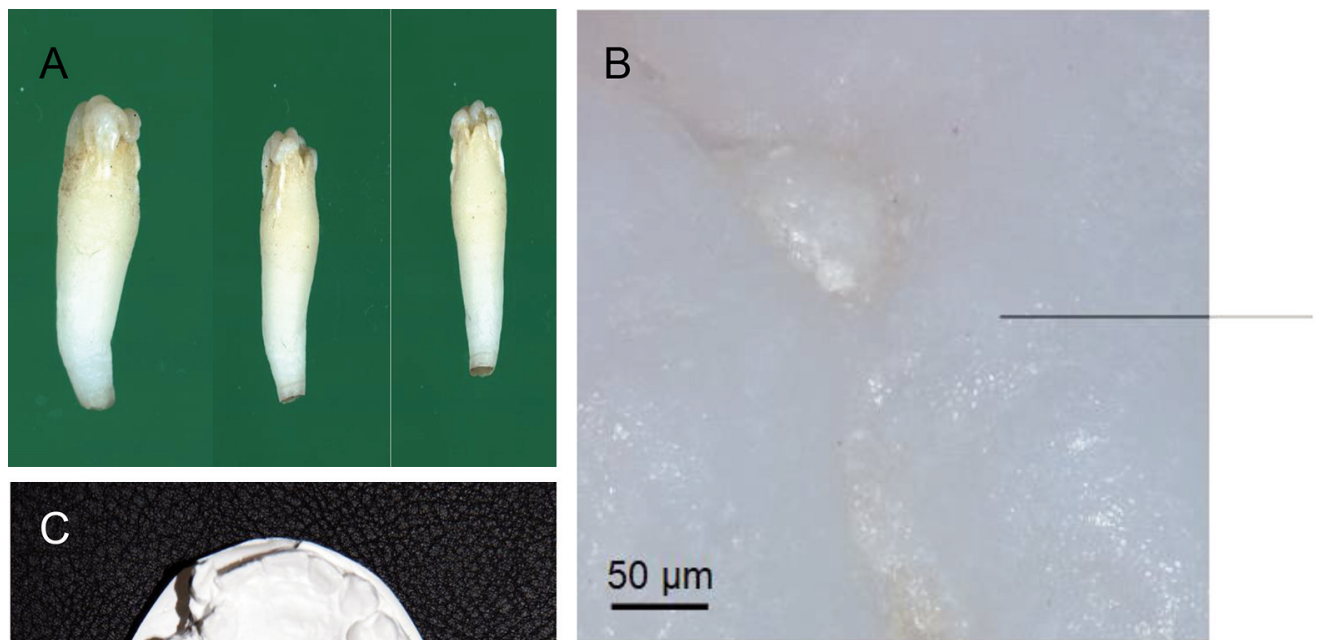

\section{Enamel}
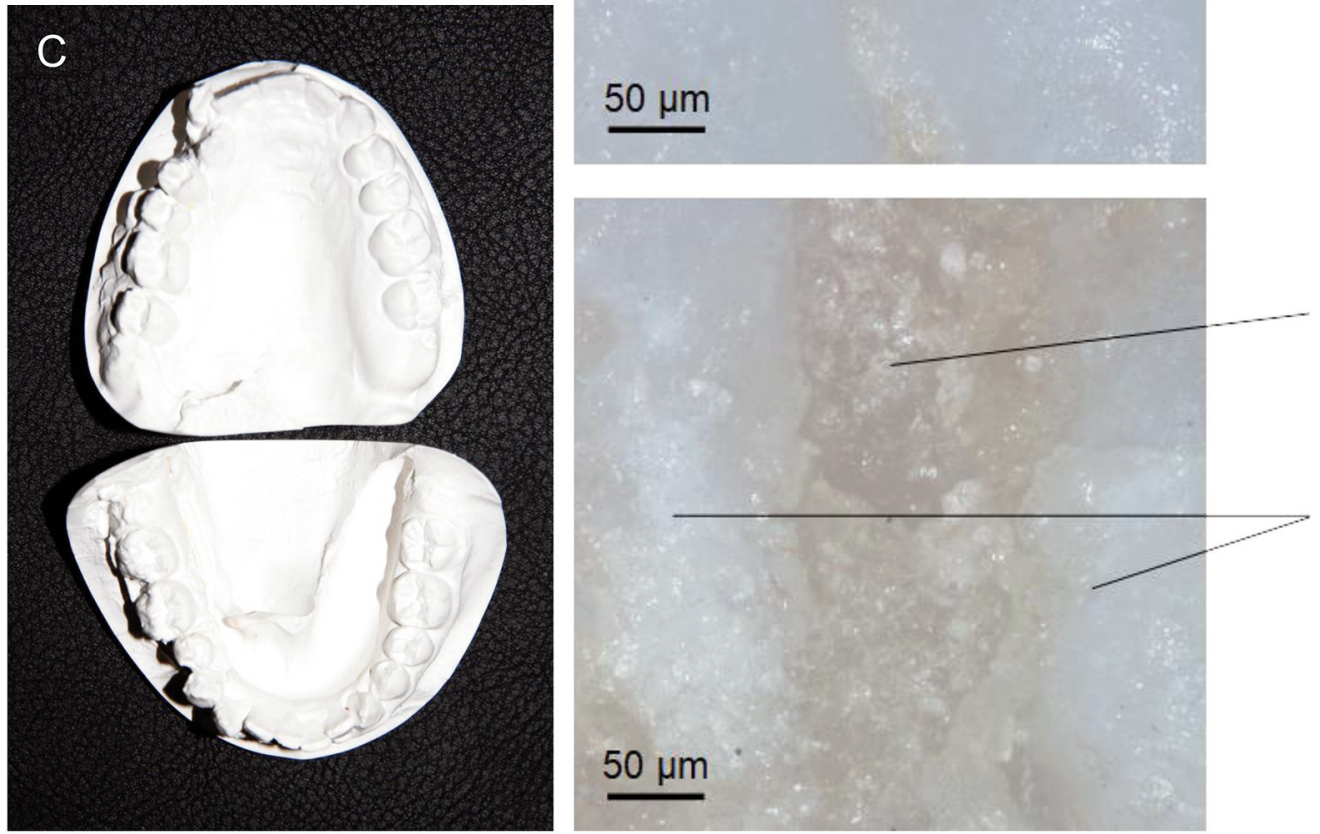

\section{Dentine covered by spotty layer of enamel}

\section{Enamel}

Figure 7. Dysmorphic teeth from a patient with nevus sebaceous syndrome. (A) A series of three photographs depicting the lower right wisdom tooth from different sides: very small crown with deep, vertical furrows within the enamel region, relative long root, wide open apex. (B) The reflected light microscopy of the tooth surface shows the only partially confluent enamel in the upper half of the image. In the lower half of the picture, the enamel cones, which run out like strands in apical direction, are interrupted by regions of irregular and thinner enamel coating. This spotty enamel coating on the root is so transparent that the dentine shimmers through. (C) Dental casts of the patient (maxilla: above; mandible: below). What is noticeable is the irregularity of the tooth position visible in both jaws on the right side, which is clearly differentiated from the harmonious contour of the dental arches on the left side. The central maxillary incisors have moved to the right (by approx. incisal width). The resulting narrowing of the maxillary teeth on the right side has resulted in the second incisor being far vestibular and the canine emerging palatal. There is also crowding of the teeth in the lower jaw. The occlusal surfaces of the molars on the right side are deeply furrowed.

In the 18-year-old patient, the wisdom teeth have emerged on the unaffected side (Figure 5). On the affected right side, the root development of the impacted upper wisdom tooth has hardly changed since the previous picture 7 years ago and is significantly behind the development of the left upper molar. In contrast, the lower, micro-morphic, also retained wisdom tooth has developed a very narrow radiopaque enamel layer on the occlusal side, which is flatty contoured. The root is relatively long and narrow compared to the root of the lower left wisdom tooth. However, the maximum diameter of the right lower wisdom tooth' root is larger than that of the crown (Figure 5B). Both OPGs do not show any asymmetries in the jaws.

However, cone beam computed tomography (CBCT) of the jaws shows a nasopalatine canal displaced to the affected side (Figure 6A, B). Both the nasal and the oral foramen are on the right. The nasopalatine canal does not show an unusual course (Figure 6B). The topographical relationship of the canal with the position of the anterior teeth shifted towards the affected side is interesting. The lack of space in the right upper canine and premolar region of the dental arch is also due to the lateralization of the anterior teeth to the right 


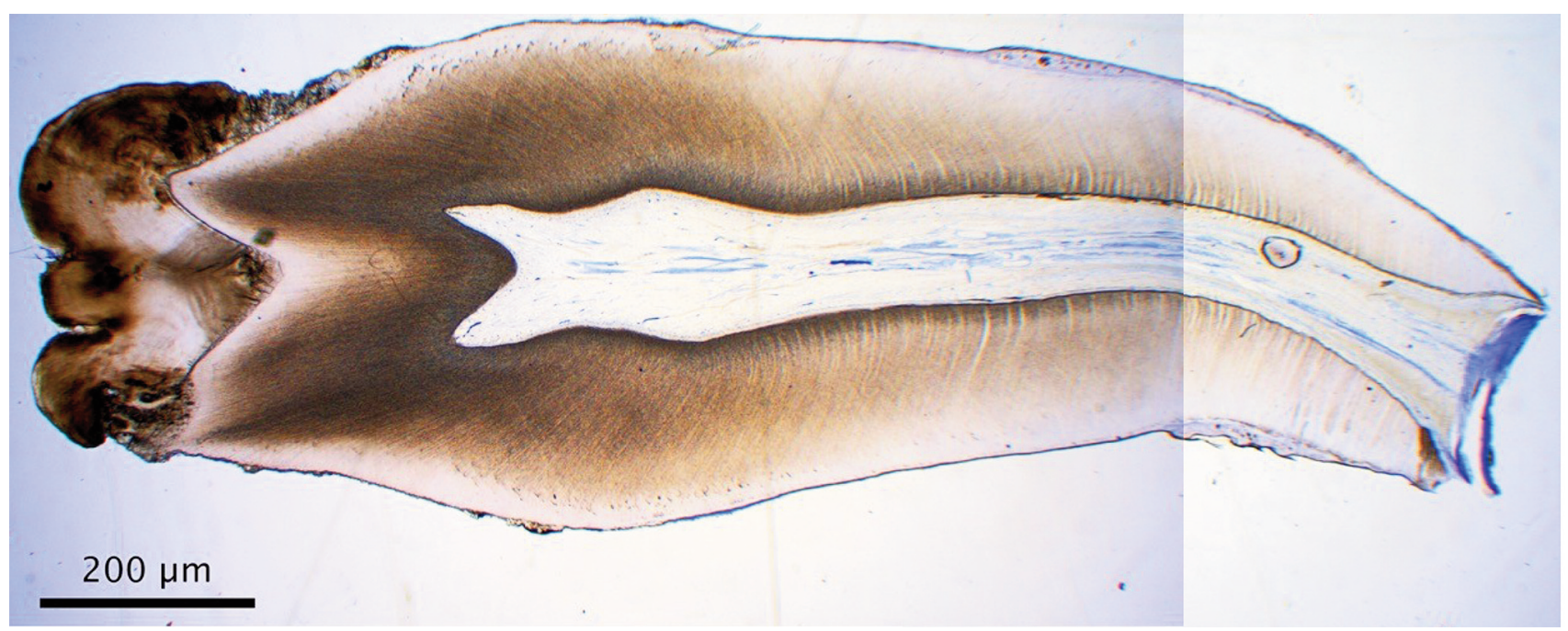

Figure 8. Cross-section of the lower right wisdom tooth of a patient with oral manifestations of the nevus sebaceous syndrome, undecalcified specimen, sawing and grinding (Säge-Dünnschliff) technique (composite image). In the micro-morphic tooth crown, below the occlusal surface, some strip-shaped densifications run parallel to the surface, others point perpendicular to the surface and approximately to the respective center of the cusps. In the center of the crown, near the dentine border, there are strands-like densities running at an angle to the center line of the tooth. The figure is somewhat reminiscent of a fir tree. The boundary between enamel and dentine is sharp. In the upper part of the picture there are focally transparent, uneven extensions of the enamel. The dentine forms two cusps resembling rudimentary protrusions under a tooth crown. In the dentine, radial stripes converge from all sides to the broad pulp. The pulp ends approximately at the level of the thin enamel protrusions, which end on the occlusal part of the root. In the root, there is a denticle in the apical third. The apex is wide open.

because the topographical relationship between the roots of the (central) incisor and the incisive foramen is preserved and therefore, both teeth with the deformed incisive bone are lateralized to the right. CBCT offers further discrete differences in bone development: the arch of the hard palate is positioned a little further cranially on the right side and the right side of the maxillary alveolar process is vertically shortened compared to the other side (Figure 6C). The mandibular canal is developed symmetrically in this crosssectional image. The patient treatment documentation proves the retention of the right maxillary anterior teeth by the papillomatous mucosa, which could only emerge after the surgical ablation. The constellation of the findings on CBCT suggests that the mucosal malformation is associated with a discrete deformation of os incisivum and thus has contributed to the anterior tooth misalignment described above.

Teeth. The eruption of several permanent teeth was hampered by the thick, papillomatous mucosa. The surgical exposure of the teeth facilitated rapid tooth eruption. In the lower jaw, the permanent teeth were aligned with the row of teeth. In contrast, both upper right lateral incisor and canine have erupted outside the row of teeth (Figure 6A). The significant misalignment of the emergent, periodontally damaged, dysmorphic, and severely loosened right upper lateral incisor to the dental arch is presumably influenced by the local bony alteration. The numerous indentations and corrugations of both tooth crowns run in a coronal-apical direction, identical in pattern compared to the extracted lower wisdom tooth and other affected teeth on the right body side. Permanent preservation of the lateral incisor is unlikely.

The brownish discoloration of several teeth on the right side is noticeable (Figure 1 and Figure 2). However, the upper left first incisor is also affected by this discoloration. Therefore, lateralization of dental findings to the right side is obvious, but incompletely realized. The discoloration of tooth crowns indicates mineralization defects. This finding is limited to the teeth of the region affected by the hyperplastic mucosa that shows slight midline crossing like the tooth malformation. These mineralization defects on individual teeth increased in visibility during the observation interval.

The crowns of the premolars and molars (Figure 7) appear slightly smaller both in the anterior-posterior and in the vestibular-lingual direction on the right side (Figure 7A, C). Several of the crowns lack a pronounced anatomical equator and appear columnar (Figure 7C). The teeth show an irregular profile of the occlusal surface clearly different from the physiological occlusal relief of normal permanent teeth (Figure 7C). Very striking findings of the dental crowns on the affected sites are groove-like fissures and ridges, some of them running in parallels to the long axis of the tooth, others forming wedge-shaped defects (Figure 7A-C). The structural anomalies start in continuity from the lateral border of the occlusal surface. The tip of wedge-shaped 

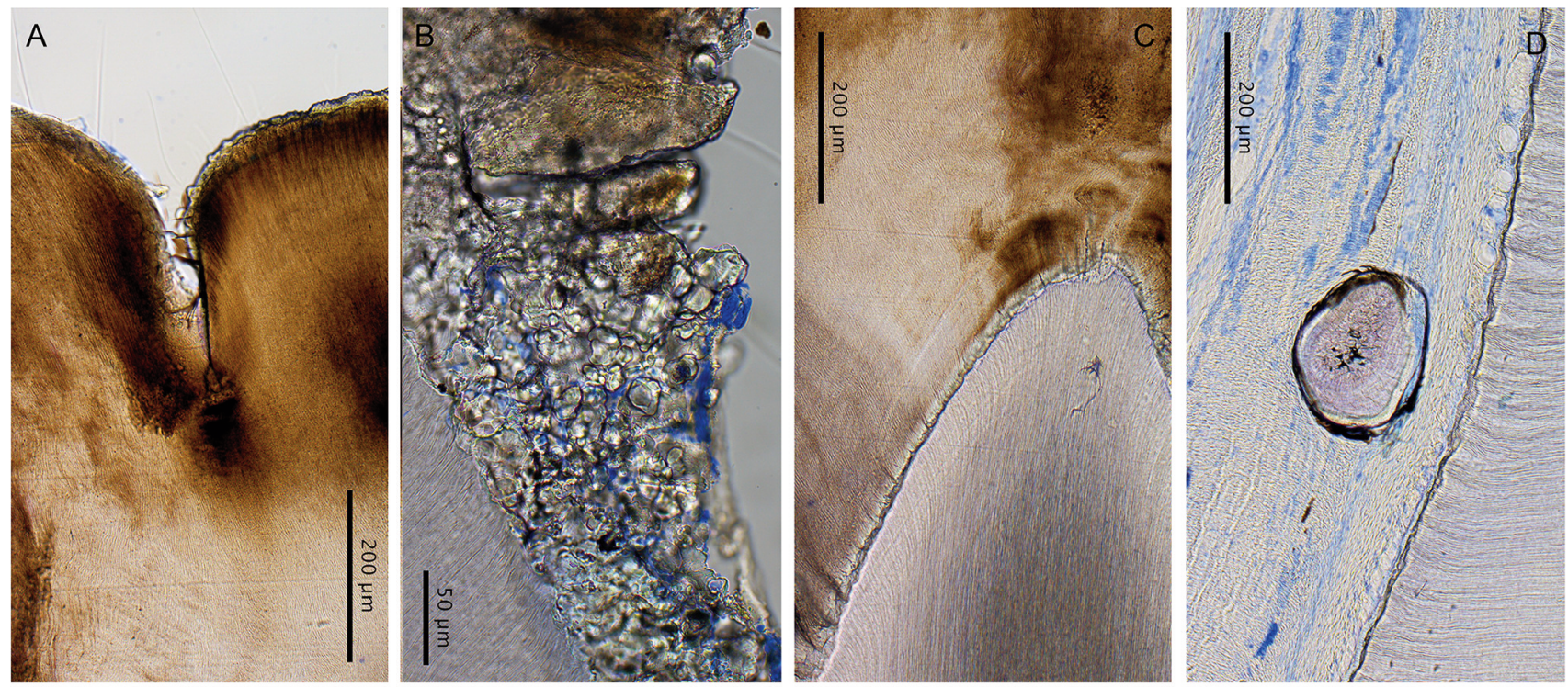

Figure 9. Detail of the microphotography of the previous figure. (A) The furrow between two small cusps is filled with transparent, pearl-like, dense structures that also lie above the surface of the cusps. However, this transparent layer of the cusps seems to be more confluent than in the furrow. The stripes running perpendicular to the surface are interpreted as Hunter-Schreger stripes. (B) Detail of the pearl-like, multilayered layer of enamel on the lateral root surface (dentine: bottom left).(C) Sharp delimitation between enamel and dentine. (E) Denticle of the pulp.

defects is directed caudally. This ribbed pattern of the vertical surfaces of the crown was also assumed for the retained and micro-morph right lower wisdom tooth depicted on the orthopantomogram of jaws (Figure 7A). The osteotomized micro-morph tooth shows hypomineralization of the crown. Detailed micro-imaging and morphological analysis disclosed substantial alterations of tooth compartments (Figure 7B).

While the right lower wisdom tooth is micro-morph in the crown area, the root of this tooth is narrow according to the crown diameter, but of considerable length. The root of the lower left wisdom tooth appears to be shorter than the dysplastic counterpart on the right side in orthopantomography at the age of 18 years. Two years after the osteotomy of the right lower wisdom tooth, the two-rooted left lower wisdom tooth has emerged into the oral cavity, increased in root lengths, and still has open dental apices. In contrast, the right upper wisdom tooth remained retained under the dysplastic mucosa, further opacified in the crown area and showed no further root growth during the last two years.

Analysis of wisdom tooth: Macroscopy. The lower right wisdom tooth has a very small crown forming several small cusps but without an anatomical equator [maximum length: $14 \mathrm{~mm}$, maximum width (root): $4.5 \mathrm{~mm}$ ] (Figure 7A). The occlusal surface is fissured, there are no approximal ridges. Tooth enamel appears to be irregularly developed and therefore spotty. There are notches on the lateral surfaces of the tooth crown that extend into the occlusal surface. The narrow root emerges with almost no transition from the crown margin. The root is roughly three times as long as the crown. However, the apex is wide open (Figure 7A).

Analysis of wisdom tooth: Microscopy of undecalcified specimen. The longitudinal section of the tooth shows the hypoplastic shape of the tooth crown (Figure 8). Small cusps are developed in the occlusal surface. The lateral walls of the small crown have only a slightly protruding enamel surface. Enamel extends caudally with a thin layer on the upper part of the root (Figure 9). The crown is covered in an irregular pattern by spherical, partially transparent, solid structures that are interpreted as enamel pearls (Figure 9A). These agglomerates are particularly common on the neck of the tooth (Figure 8 and Figure 9B). Within the enamel, Hunter-Schreger bands can be seen arranged radially to the indicated crown (Figure 8 and Figure 9A). The transition between dentine and enamel is distinct and planar (Figure 8 and Figure 9C). The pulp is developed to the level of the thin, pearl-like extensions of the enamel that cover the upper part of the root (Figure 8). No pulp is developed within the level of the crown (Figure 8). A denticle is exposed in the pulp (Figure 8 and Figure 9). The apex is wide open with channel walls diverging towards the opening (Figure 8).

Analysis of wisdom tooth: Optical coherence tomography $(O C T)$. The tooth surface was examined by means of spectral-domain OCT (OQ Labscope 2.0, Lumedica, 

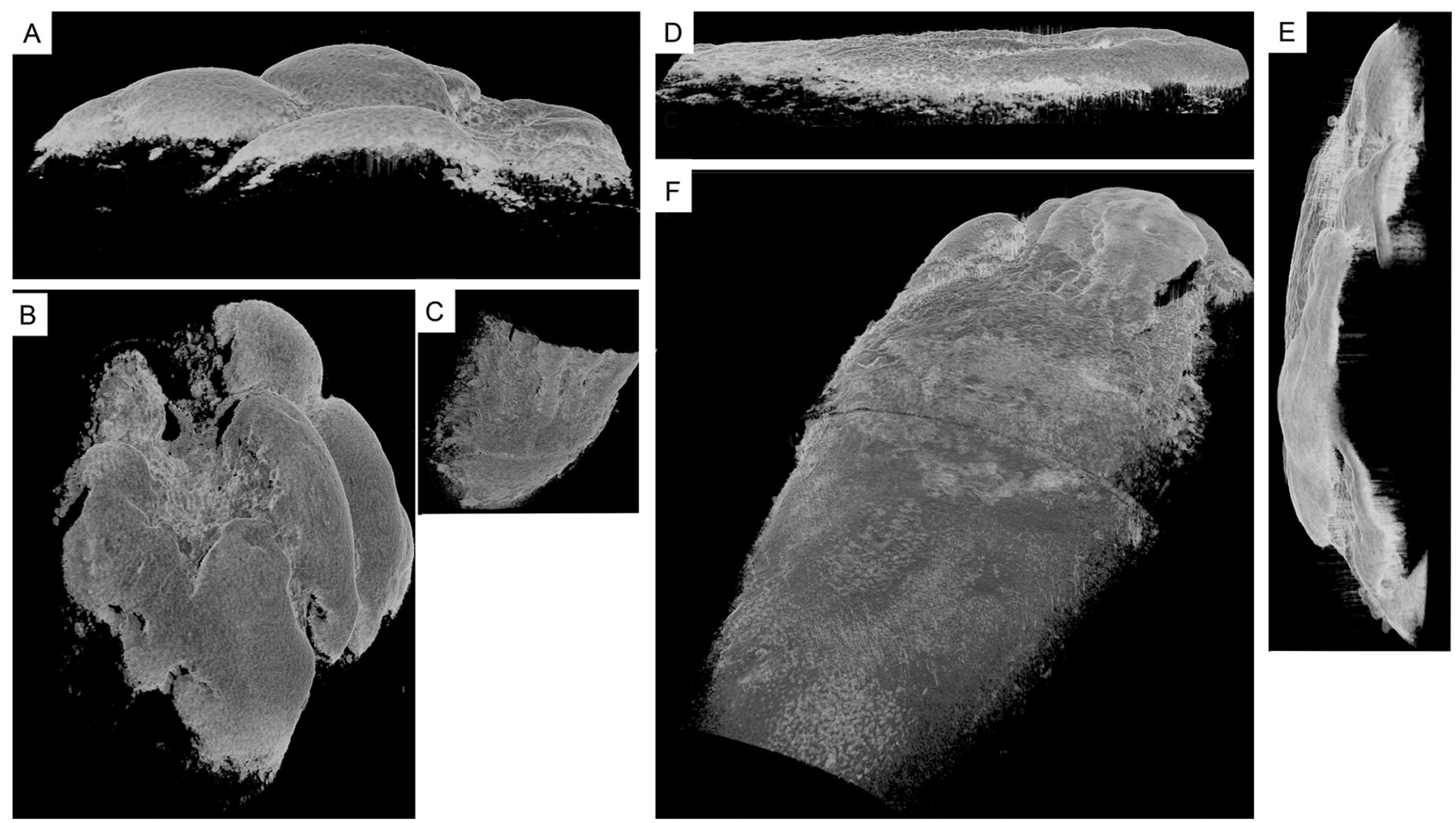

Figure 10. Optical coherence tomography (OCT) of dysmorphic lower right wisdom tooth. (A) Angled view of the occlusal surface of the tooth. Four rounded occlusal cusps are shown. Grooves are indicated between the cusps. On the right side there appears to be a border that connects two cusps. (B) Compared to (A) somewhat more vertical and more distant, lateral view of the crown region of the tooth. Now it becomes apparent that the indicated cusp-like elevations of the tooth crown extend like strands down to the cranial root region. The cusps formed by enamel surround a central defect in the middle of the occlusal surface, which is apparently not completely covered by enamel. Figures $C$-E show the strand-like extensions of the enamel on the root. $(F)$ The composite image shows the surface of the tooth's relatively large root.

Durham, NC, USA). The system operates at $840 \mathrm{~nm}$ central wavelength and offers a resolution of $15 \mu \mathrm{m}$ in lateral and 7 $\mu \mathrm{m}$ (air) in axial direction, covering a volume of about $5.88 \times 5.88 \times 1.85 \mathrm{~mm}^{3}$ (air) with $512 \times 512 \times 512$ voxels. OCT forms true to detail tooth surface, for example the miniaturized cusps of the occlusal surface, the steep slope from the cusps to the lateral crown surface, the deep furrows between the crown cusps that continue into the lateral surface of the crown, and the shallow extensions of the enamel layer on the root (Figure 10). The micro-pores of the root are homogeneously and densely distributed.

Analysis of wisdom tooth: Surface microscopy. The surface of the untreated tooth was examined microscopically (Olympus DSX 500, Hamburg, Germany) (Figure 7B). The surface of the tooth is covered by a thin layer of enamel. In many places, the enamel only spotty covers the dentine underneath.

Analysis of wisdom tooth: Micro-computed tomography $(\mu C T)$ \& quantitative backscattered electron imaging $(q B E I)$. The whole tooth was further examined using a Skyscan $\mu$ CT 1272 (Bruker, Kontich, Belgium) operated with a spatial resolution of $7.5 \mu \mathrm{m}$ (Figure 11). Imaging was performed with a $0.5 \mathrm{~mm}$ Al filter, $60 \mathrm{kV}$ acceleration voltage, $166 \mu \mathrm{A}$ tube current, and 1,800 ms exposure time. The volume of the tooth compartments impressively demonstrates arrested development of enamel underlining the findings determined with surface microscopy and advanced development of the root (enamel: $17.569 \mathrm{~mm}^{3}$, dentine: $125.545 \mathrm{~mm}^{3}$, pulp: $9.593 \mathrm{~mm}^{3}$ ). The tissue mineral density distribution of dental tissues was determined by qBEI at a scanning electron microscope (LEO $435 \mathrm{VP}$; LEO Electron Microscopy Ltd., Cambridge, England) performed at $20 \mathrm{kV}, 680 \mathrm{pA}$, and with a constant working distance of $20 \mathrm{~mm}$. The mean calcium content of the hard substances corresponded to normal values, although enamel mineralization presented with a high heterogeneity $(\mathrm{Ca} /$ Width $)$ which was based on low mineralized areas $(*)$ within the enamel matrix (Figure 12).

Genetics. The patient's DNA was extracted from the tissue samples, amplified using PCR and sequenced according to Sanger on an automatic sequence analyzer (ABI3500XL, Thermo Fisher, Waltham, MA, USA). The determined 

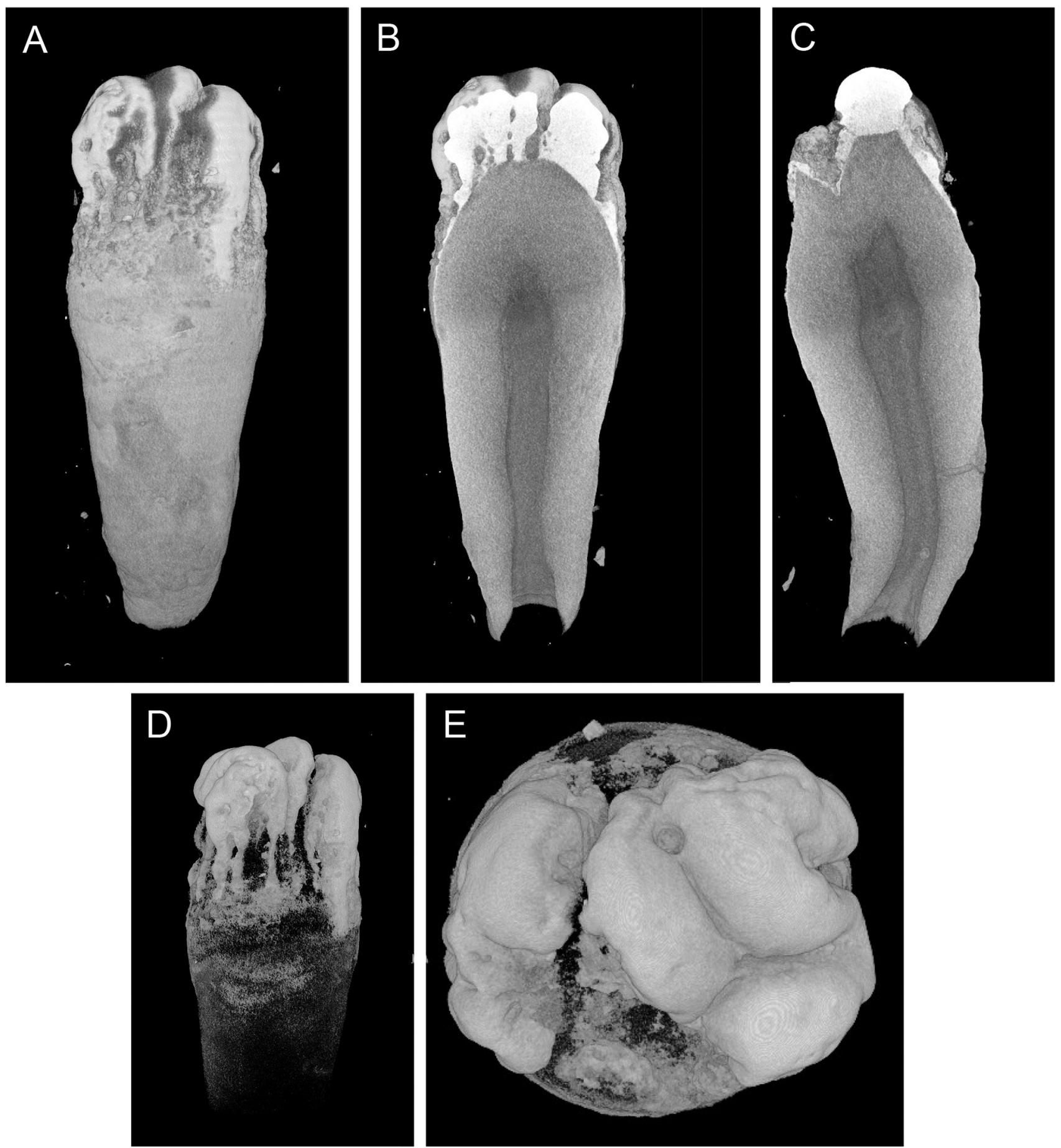

Figure 11. Micro-computed tomography of dysmorphic lower right wisdom tooth. (A) Side view. Irregularly configured, small, cusp-like occlusal surfaces that taper apically like strands without developing an anatomical equator. The strand-like migrations of the odontogenic epithelium manifested in the enamel are of considerably different diameters. Likewise, the outer extensions of the enamel on the tooth root are of different distances. (B) Cross-section of the tooth. The disproportion between crown size and root size is evident. Furrows wipe the cusp-like crown rake up to the enamel-dentin border. The boundary between dentine and enamel is sharp. (C) The cross section of the tooth shows the different sizes. pearllike enamel formations in the crown area and in the transition to the root. The pulp approximately reaches the level of the fusion line and forms initial protuberances, probably analogous to the development of a coronary pulp. The almost horizontal canal between the pulp and the tooth surface at the transition from the middle to the apical root third is noticeable. (D) Another lateral view of the crown area to visualize the strands of enamel that appear to have coagulated when the ameloblasts migrate apically. (E) Occlusal view of the tooth. Several small cusps with craterlike occlusal defects and deep furrows in the occlusal surface. The top view shows the speckled covering of the upper root with enamel. 

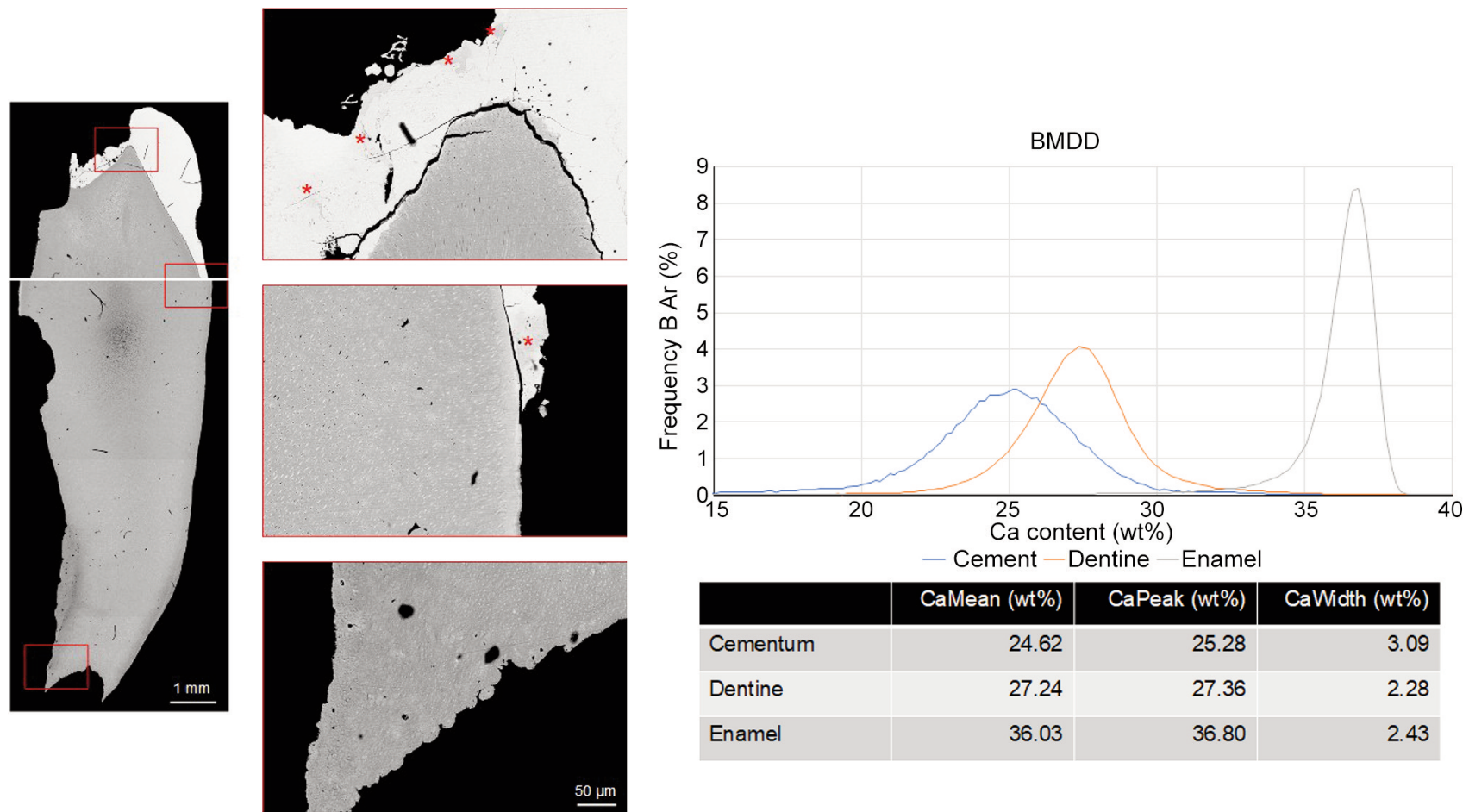

\begin{tabular}{|l|r|r|r|}
\hline & CaMean (wt\%) & CaPeak (wt\%) & CaWidth (wt\%) \\
\hline Cementum & 24.62 & 25.28 & 3.09 \\
\hline Dentine & 27.24 & 27.36 & 2.28 \\
\hline Enamel & 36.03 & 36.80 & 2.43 \\
\hline
\end{tabular}

Figure 12. Elemental analysis (calcium) of the dysmorphic wisdom tooth developing in the mandible covered with papilloma-like mucosa in a patient with nevus sebaceous syndrome. The left figure shows the entire tooth (composite image) and the three regions of the measurement displayed in detail (above: enamel/dentine border of the crown, middle: enamel/dentine border of the root, below: apex). The graph shows the calcium content of enamel, dentine, and cement.

sequences were compared against the reference sequence. The following genes/exons were examined: KRAS (NM_004985) exon 2 and 3; HRAS (NM_005343) exons 2 and 3; NRAS (NM_002524) exons 2-3. A somatic mutation in $H R A S$ was detected in several samples of the mucosal changes. The proportion of the pathogenic sequence variant c.37G $>$ C p.Gly13Arg was around $33 \%$ in the palatal gingiva, around $14 \%$ in the buccal gingiva of the upper jaw, and around $13 \%$ in the buccal gingiva of the lower jaw. The mosaic mutation was not recorded in adjacent unaffected mucosa.

\section{Discussion}

This investigation describes the long-term course of treatment of orofacial skin alterations in a patient with NSS. Detailed morphological analysis is presented of a dysmorphic, retained wisdom tooth of the affected oral region. The upper extremity malformation arising contralaterally to the orofacial findings likely is related to the syndrome. The proven HRAS mutation in the affected oral mucosa is considered a characteristic genetic alteration in skin findings of NSS patients (14).
Nomenclature. Nevus sebaceous syndrome (NSS) or Schimmelpenning-Feuerstein-Mims (SFM) syndrome [Online Mendelian Inheritance in Man: 163200 (phenotype number)] is a rare neurocutaneous syndrome classified in the group of organoid ENS $(29,30)$. The number of synonyms for the syndrome is very large (31). Schimmelpenning described the diagnostic triad of nevus sebaceous, cerebral, and ocular findings and introduced diagnostic criteria for a new syndrome (29). However, many researchers have contributed to the characterization of the syndrome revealing substantial variability of phenotype and characteristic skin lesions (30-42). Pathological findings in NSS go beyond the spectrum of organs that constitute skin, eyes, and nervous system $(31,42)$. On the other hand, it became apparent soon after delineation of the syndrome that neither cerebral nor ophthalmological findings are mandatory for diagnosing NSS (32). In other words, the concept of the later so-called mosaicism of genodermatoses $(6,8,19,24)$ was anticipated at an early stage of applied (molecular) genetics in NSS diagnostics because well-circumscribed solitary lesions and oligosymptomatic cases with skin lesions were assessed as findings potentially related to the syndrome's spectrum. Diagnosing the syndrome is independent of the lesion's size 
and this statement also applies to NSS patients with oral manifestations $(33,44)$. However, the wide variation in the phenotype has led to uncertainty as to which constellation of clinical findings justifies the diagnosis of NSS. For example, authors have detailed a case of ENS with multiple cranial linear epidermal sebaceous nevi and several oral lesions of epithelial origin but explicitly excluded NSS diagnosis, presumably because neither ophthalmological nor neurological findings were recorded (45). Craniofacial NS is a common feature of NSS (31).

Scientific communication on the syndrome is difficult due to the contributions of a large number of authors, the many (eponymous) designations of the syndrome, the very variable and unavoidably subjective evaluation by later reviewers concerning the respective researchers" achievements in the characterization of the sporadic nevus as well as the syndrome, and - based on the variable verification of sources - different historizing prioritization of individual authors reporting on the subject $(3,46)$, which can hardly be overlooked by any reader. Another difficulty in the nosology of the phenotypes lies in the fact that certain combinations of findings can be decisive for the selection of patients for a study group (47), which represent only part of the syndrome features for other examiners (8). These terminological inconsistencies (48) also make it difficult to assess the few reports on oral manifestations of ENS, especially in previously published work (46).

Dissemination and exchange of scientific data has increased precision by omitting eponymous designations of the syndrome and consistent use of the term 'nevus sebaceous syndrome' (NSS) as an umbrella term (12). In addition, the understanding of the disease has been significantly improved by molecular genetics detecting frequent, identical mutations in genes performing control functions for cellular proliferation. These insights allow the merging of differently termed nevus syndromes characterized by different skin lesions as phenotypical differences of a single entity arising from a common genetic cause, i.e., mutations in RAS genes $(14,15)$. The standardization of terminology based on genetic characteristics can also form the basis for further information on oral manifestations of the syndromes and on factors influencing regular dentition.

Skin. Epidermis of the face, oral cavity and neck have different histological components that reflect the origin of the integument from different germ layers and respective specialization, e.g., epithelial cells and vessels. The pattern of certain congenital skin lesions is assessed as a trace of migrating, epithelial cells from the embryonic period, which have become visibly through mutation-induced incorrect differentiation. The different composition of the nevi is considered by some authors an indicator of both time and place of embryonic differentiation of the cells. Due to the variable number and differences of cells constituting skin appendages, some nevi appear like simple accumulations of altered cells and others show 'organoid' differentiation and are addressed as hamartomata. Malignant tumors rarely arise from $\mathrm{EN}(34,49-53)$. The distribution pattern of the facial nevi follows the Blaschko lines (53). Usually, the lesions are limited to defined areas of the body. However, in rarely reported cases, even one half of the body can be affected. In these cases, oral soft tissue can show typical alterations (50).

Oral cavity. Oral findings are well known in ENS, but have rarely been reported $(5,46)$. Evaluation of previous reviews of oral manifestations is severely limited by the timedependent inclusion criteria for defining a nevus and rating a case of sporadic or syndromic nevi (46). The very differently applied diagnostic criteria impair the evaluation of syndromeassociated oral lesions (54). For example, precisely reported findings on linear oral nevi have been classified as nonsyndromic because the investigators claim that the patients did not present CNS, skeletal and ophthalmological changes. However, the authors were not referring diagnostic imaging results that can reasonably substantiate exclusion of diagnoses relevant for this statement (54). On the other hand, strictly unilateral (linear) oral papilloma with no further signs of syndromic disease is rare $(55,56)$. The discussion focuses on orofacial manifestations in NSS.

Oral manifestations of NSS.

Types of lesions. Oral manifestations of NSS include mucosal hyperpigmentation (47), papillomatosis, eventually causing soft tissue overgrowth on teeth (54, 56-64), and enamel defects (26), furthermore, hemihypertrophy and fibrous lesions $(27,50,59-62)$ and enlarged papillae fungiformes of the tongue (33), uvula bifida (60), retention of teeth (26) and tooth position anomalies (33), numerical aberrations and dysmorphia of teeth $(54,59,63-66)$, bone cyst of jaw (59), giant cell granuloma of the jaw $(27,60)$ or 'osteoclastoma' (39), odontoma (67), and further odontogenic neoplasms such as ameloblastoma $(35,45,68)$, ameloblastic fibro-odontoma (69), and adenomatoid odontogenic tumor $(44,63,64)$. Basal cell carcinoma (BCC) is a feature of NSS, e.g., of lips (50). However, BCC is rarely diagnosed in $\operatorname{EN}(34,51)$.

Infrequent reporting of oral lesions. While the cutaneous differentiation disorders in patients with ENS are usually registered at birth or in early childhood, time of visible occurrence of oral findings is hardly documented $(18,20$, 40). Few authors explicitly point out that they have excluded local findings in an ENS/NSS patient by oral examination (41) or that oral examination could not or only inadequately be carried out (37).

Rogers et al. (11) examined 131 patients with epidermal nevi (head and neck affected: $42 \%$ ). In $33 \%$ of the cases 
anomalies of other organ systems were registered. In one case, an oral finding (tongue-tie) was reported which, due to its frequency in the general population, was rated as likely coincidental. A systematic oral examination of the patient is not mentioned in the report, but it can be assumed that EN and syndrome-related oral findings rarely develop combined both in sporadic and syndrome-related cases.

A report by Baliga et al. (67) described symptomatic oral erythematous mucosal hyperplasia ('redness of gums') in a 17-year-old patient who had observed these oral findings about 5-6 months prior to medical consultation. In contrast, the extensive linear craniofacial nevi were known since birth. It is open to discussion whether topographically associated lesions in the oral and craniofacial regions arise at the same time or metachronous. Interestingly, the tumorous swellings in both jaws caused by ameloblastoma in one case of ENS were without oral mucosal manifestations of the syndromic disease. However, the patient had developed characteristic facial skin lesions (68).

In the present case, the initial examination of the newborn infant is without documents providing information about a thoroughly performed oral inspection. The considerable oral involvement in a syndromic patient is only registered several months later.

Impact of physical development on skin lesion's characteristic. The evaluation of literature concerning oral findings in patients with ENS is made difficult on the one hand by the inconsistent terminology (46). Many reports describing anomalies of the skeleton, eyes, or oral cavity in NSS do not reveal a clear definition of the associated EN and vice versa (5). On the other hand, it must be considered that sebaceous nevi of the skin may be absent in young NSS patients $(11,26,70)$ and only appear with further physical maturity (71). Therefore, reports of oral findings in young patients with an ENS may contain cases who had not yet developed any sebaceous differentiation of the nevus at the time of the investigation (71) and were erroneously excluded from considering NSS.

Impact of topography on oral lesion characteristics. The papillomatous mucosa in NSS has no sebaceous components. This finding corresponds to the normal development of oral mucosa (57). Histological examinations have shown that lesions with continuous transition from skin to oral mucosa have no sebaceous differentiation in the oral parts (60). The report of a sporadic nevus sebaceou of the oral mucous membrane is a rarity that points to the common origin of skin and oral mucous membrane (71).

The verrucous palatal lesions of this case are consistent with the findings of previous reports $(26,45,57,72)$. The oral hyperplasia of the mucosa is known as the papillary intraoral epithelial nevi (72). It has been suggested that individual cases with unilateral papillary hyperplasia of the oral mucosa - analogous to the striate nevi of the skin represent minimal variants of the NSS (33).

The oral papillomatous lesions are in most cases unilateral and in the case of muco-cutaneous (orofacial) manifestations on the side of the cutaneous lesions, but the lesions can arise also in the midline of oral cavity and extend bilaterally (45), in the same way as cutaneous manifestations.

Histology of oral soft tissue lesions. The histological examination of the papillary, partially pedunculated masses showed broad, connective tissue papillae with ortho- and parakeratinizing squamous epithelium. None of the lesions showed signs of dysplasia. Differences in the histological findings between the initial manifestation of oral papillomas and recurrences were explained with reference to local, inflammatory factors [plaque and calculus accumulation (57)].

Late onset of mutation effects on certain oral tissues. Molecular genetic diagnostics provided data to assign the temporo-spatial variable clinical findings to mutations arising during different phases of prenatal development (3$6)$. Some oral findings are recognized around birth and others develop and change with age, potentially related to the individual's physical maturity (vide supra). The pattern of the dysmorphic crowns is uniform on both permanent teeth with precursors (replacement teeth: premolars, canine) and without deciduous ancestors (molars). Some findings are an example of the fact that certain manifestations of the disease cannot develop until the postnatal period (73), e.g., structurally altered second or third molars like in the present case. Radiologic evidence of initial wisdom tooth development is limited to postnatal life (75). As shown by histological examination of wisdom tooth specimen and clinical investigation of permanent dentition, one genetic alteration has had similar effects on at least part of several organs (dental crown) that may appear on radiographs prenatally (canines, premolars, first molar) and postnatally (second and third molar). The identical tooth changes of the affected jaws' side document a long-lasting impact of the disorder on enamel-forming and dentin-forming cells during embryogenesis and postnatal life. In the presented case, the dysplasia of the enamel appears with vertically aligned corrugations both in the erupted premolars, first and second molars as well as in the retained, wisdom tooth with micromorph crown. The uniform pattern of dental developmental disorder with particularly noticeable dysmorphic crown formation comprises several, individually developing organs and a development phase lasting many years. The groovelike indentations formed in the same way on the micromorph wisdom tooth testify to the long-acting prenatal migration and association errors of certain neuroectodermal cells in the oral developmental field resulting in anomalous 

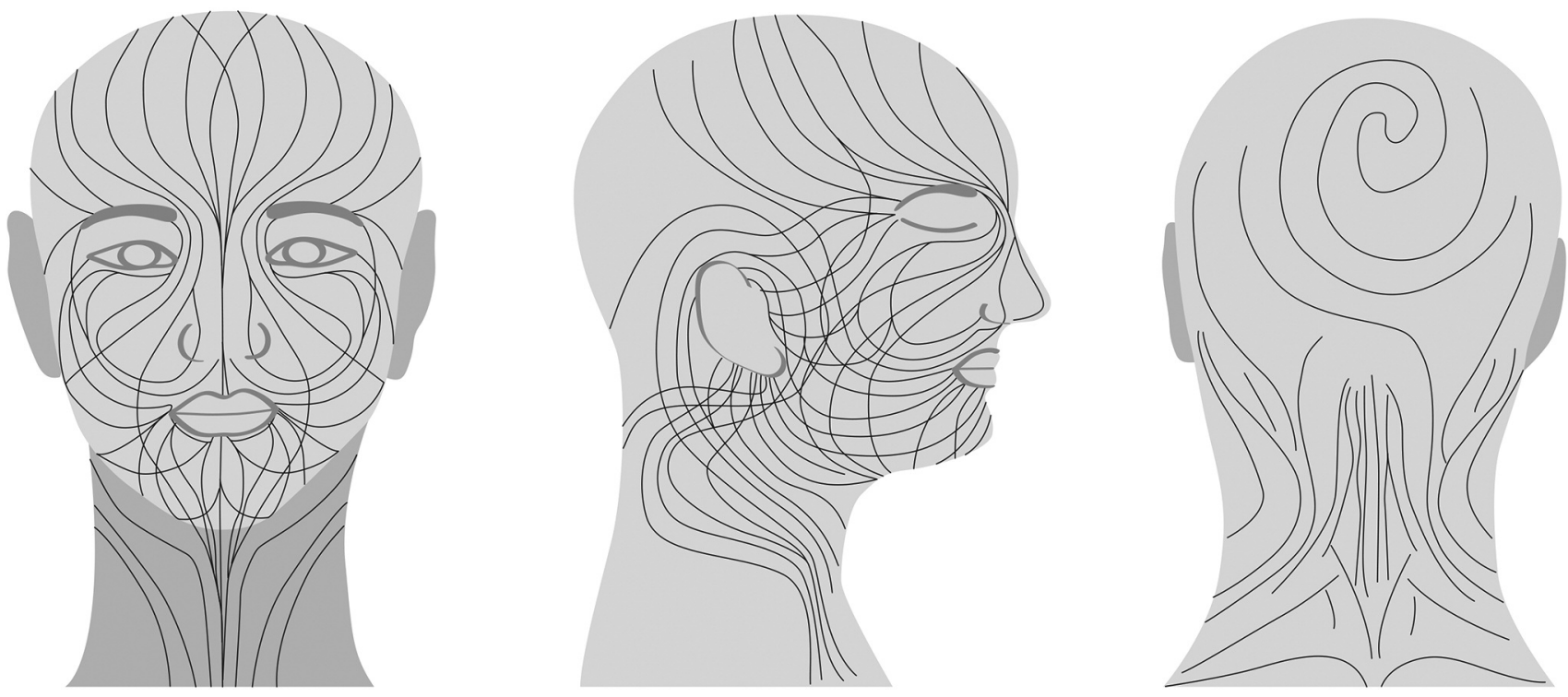

Figure 13. Blaschko lines of the head and neck (adapted from (53)). Interestingly, in this scheme, the upper lips are omitted from Blaschko lines in frontal view. However, nasolabial, string-like and slightly curved nevi can touch the upper lip laterally (middle diagram). The skin of the lip appears spared from the lesions. However, in the presented case there were occasional slightly raised lesions within the skin of the lip, which were similar in structure to the rest of the nevi in the region (Figure $1 \mathrm{~A}, 1 \mathrm{~F}, 1 \mathrm{G})$. The course of the patient's perioral nevi approx. follows the lines shown in the scheme.

crown surface and tooth shape. Enamel dysplasia and other disorders of regular tooth morphology are well known for patients with ENS. Some authors suspect the wedge-shaped enamel defects that are conspicuous in some patients are the dental equivalent of the embryonic migration traces of epithelial cell clusters described by Blaschko for the developing skin $(76,77)$. The dental morphology in orally manifest malformations of the ENS has been described only cursorily. To our knowledge, there is no information about changes in the deciduous teeth in ENS. It is desirable to obtain reports on the dental morphology of deciduous teeth in ENS patients with oral findings to compare whether the structural changes of the teeth demonstrated in the present study are already detectable in the predecessors. The dental status of deciduous dentition can be assessed retrospectively from the documentation of the child's oral findings. The teeth were fully developed and emerged. Focal defects in enamel formation are documented.

The uniform findings on the tooth crowns of permanent teeth prove the structure-changing competence of the enamelforming cells of the affected region, only some of which were already established in the fetal period. The findings in the lower right wisdom tooth are identical to other teeth of the affected regions and is interpreted as phenotypic evidence of the effects of a postzygotic mutation in a wide oral developmental field of cells derived from neural crest (65). Indeed, some authors suspect that the visible line-shaped courses but also the plaque-like expansions of the epithelial lesions depict the embryonic migrations of cells that originate from the neural crest (3). In an analogous way, the notches or teardrop-like arrangements of the enamel are assessed as residues of embryonic dysfunctional cell migrations. The impact the presumably causative RAS mutation on the dentition and on oral tissue development is effective even in an organ that develops many years after birth. Current pathogenesis models of EN assume that postzygotic pluripotent cells are affected by pathogenic mutations and therefore, depending on the individual's developmental stage, epidermal nevi can arise with and without extracutaneous involvement $(5,48,74)$.

Oral Blaschko lines. The transition of the facial nevi to the lip and oral mucous membrane, which has been reported in individual cases, gave rise to the assumption that the distribution lines of the nevi reported by Blaschko could also be transferred to oral territories (60). However, to the best of our knowledge, Blaschko lines are not defined for the oral cavity (53) (Figure 13). The reports of oral lesions in connection with epidermal nevus syndromes illustrate unilateral, bilateral, midline-associated and - in this case unilateral locations with a discrete midline crossing (54).

Teeth. Vertical grooves of dental crowns were recorded in other genodermatoses as well (76). For example, clinical diagnosis of X-chromosome linked focal dermal hypoplasia (FDH, synonym: Goltz-Gorlin syndrome) was supported by 
the record of visible structure anomalies of frontal teeth (78). In the published FDH case, the shape of affected upper incisors was not altered and findings were bilateral. The wedge-shaped enamel defects are like the finding of the current NSS case. The authors' conclusion the dental anomalies are possibly unique to FDH are not supported by the findings presented. However, bilaterality of dental findings may be a distinguishing factor between enamel dysmorphology of FDH and NSS.

Bone (extragnathic). Bone findings are extremely variable in ENS. Bony changes frequently were noted ipsilateral to the skin lesions (79). However, contralateral or bilateral skeletal findings were reported in NSS relative to skin findings (79). Some authors deduce from literature analysis that skeletal changes can be diagnosed in around $50 \%$ of cases in NSS (31). The spectrum of bone changes in NSS includes local defects, irregularities in the bone contour and surface (20), altered size of individual bones, in particular bony enlargement (79), and more generalized findings such as osteopenia and hypophosphatemia vitamin D resistant rickets (79).

Duplication of phalanges and syndactyly has been described for ENS $(11,42,80,81)$. Combinations of oral findings and malformations of the phalanges are known for ENS (1, 36, 82). However, syndromic polydactyly is very numerous (83) and in the present case it cannot be ruled out that there was a coincidence of a predominantly right-sided NSS combined with a sporadic contralateral duplication of a finger that must be related to a pathogenesis different from NSS.

Genetics. ENS are sporadic diseases (3) arising due to postzygotic mutations (38). Recent studies provide evidence for postzygotic KRAS, HRAS, NRAS, and FGFRl hot-spot mutations being involved in the development of lesions that arise in ENS (14-18, 20, 22, 84). The common activation pathway of the HRAS/KRAS mutations causes constitutive activation of rapidly accelerated fibrosarcoma kinase (RAF) -mitogen-activated protein kinase (MEK) -extracellular receptor kinase (ERK) and phosphoinositide 3-kinase signaling pathways (52). The result of these activations is accelerated cell growth. HRAS mutation c. $37 \mathrm{G}>\mathrm{C}$ is characteristic of patients with NSS (19). It was pointed out (52) that this HRAS mutation was detected in more than $95 \%$ of the known cases of sporadic or syndrome associated sebaceous nevi (19) and in further tumors arising with in NSS, for example in syringocystadenoma papilliferum, trichoblastoma and trichilemmoma (15).

The mosaic status of the RAS mutations in EN was proven by analyzing the distribution pattern of the mutations: The mutations were detectable in the keratinocytes of the affected skin regions, but not in the fibroblasts underlying the altered epithelia $(14,15)$. This mutation distribution pattern was confirmed in oral lesions of this study.
$H P V$. HPV apparently has no role in the pathogenesis of NS (55, 85). HPV 6, 11, 16 and 18 were excluded in all cutaneous lesions in a recent study on children with sporadic NS (85). The authors refer to RAS mutations identified in NS with the suspected consequence of increased cell proliferation of affected (epithelial) cells (14). The findings were interpreted as a sufficient cause for the development of the nevi (85). However, later colonization of the lesions by HPV in adolescence or adulthood is assumed to be a plausible mechanism to explain HPV in NS as already described in earlier studies (86). The acquisition of HPV in already established cutaneous lesions is very likely $(85,86)$. So far, oral papillomatous lesions in NSS have not been screened for HPV. The detection of HPV 6, which is unique in this study, does not seem to have any pathogenetic significance for the oral lesions because contamination with the virus is equally common in normal and papillomatous oral mucosa (87).

Therapy. The course after surgical treatment shows that localized lesions of the skin can potentially be completely removed without causing local recurrences. This assessment also applies to the gingiva (54). In contrast, the reductions in the papillomatous mucous membrane in other oral areas, especially on the hard and soft palate, are substantial and permanent (71). In contrast, the frequent and usually rapid reorganization of the oral papillomatous mucosa after extensive ablative surgery confirms the wellknown high recurrence potential of lesions (57). Apparently, complete removal of the lesions in the periodontal area has been not achieved and the residual changed tissue was able to regenerate the altered mucosa almost completely in the original area of expansion in dentate regions. The course of treatment also shows that unaffected mucous membrane mobilized from the vestibulum and the cheek to cover the exposed bone and circumferentially fixed around the teeth has been replaced by the recurrent erythematous lesion. The repeated observation of the replacement of transplanted normal mucosa by papillomatous epithelium is unusual, especially when considering the relatively large area that was removed and covered by normal epithelium by surgical assistance. Since the adjacent connective tissue has a considerable influence on epithelial differentiation, it can be speculated that at least some connective tissue cells of the alveolar process covered by the papillomatous mucosa are also affected by the genetic change. However, the distribution pattern of the RAS mutation speaks against the assumption of connective tissue genetic changes in the lesions because the mutation has only been detected in the epithelium.

Surgical treatment of cutaneous nevi is determined by topography and size of the lesions. If the excision of the nevus is complete, no local recurrence is to be expected. Our follow-up of patient showed that the correction of cervical 
scars, which had arisen after excision from NS, showed no evidence of skin appendages in the examination of the tissue samples. On the other hand, the sebaceous lesions of the nose recurred within months or years after partial excision for esthetic reasons.

In principle, the ablation of the affected mucosa should create conditions for re-epithelialization of the defect with normal mucosa. In fact, to cover the defects after ablation of the papillomatous mucosa, a large-area transposition mucosa plastic from the vestibulum and the floor of the mouth was chosen. However, experiences have been reported on ablative surgery and early recurrence of papillomatous lesions. Recurrence remained stable for 15 years after initial presentation and therapy (72). Other authors have reported long-term success after ablation of oral lesions (54). The high recurrence rate of oral lesions $(45,57)$ was confirmed during treatment of the presented patient. Nevertheless, the surgical measure made sense because the patient's strong bleeding predisposition of the lesions and the tumor-like growth of the mucous membrane visible when the mouth is opened was found to be very uncomfortable. Furthermore, the high vulnerability of the mucosa means that oral hygiene of the affected teeth is neglected. The unusually rapid development of teeth affected by heavy dental plaque and calculus, which is noticeable in this case and in earlier reports (57), is probably due to the mechanical predisposition of impaired oral hygiene which favors rapid accumulation of plaque. Other authors suspect that the constitutive inflammatory factors of the changed epithelia contribute to the proliferation of the lesions (45) with the consequence of overgrowing mucosa, formation of pockets and degradation of adjacent bone. Advanced regression of the alveolar limbus in this case was conspicuous in the right upper premolar and canine region (Figure 5A).

\section{Conclusion}

Oral manifestations of NSS involve hard and soft tissues. The surgical treatment of oral soft tissue hyperplasia leads to substantial reduction of papilloma. However, periodontal papilloma reduction had no long-lasting effects on oral hygiene conditions and only moderate aesthetic improvement of the dentoalveolar complex. Odontodysplasia in the affected area indicates the complex influence of mosaic RASopathy on dentition.

\section{Conflicts of Interest}

The Authors have no conflicts of interest regarding this work.

\section{Authors' Contributions}

Treatment of patient and study design (REF), drafting the manuscript (REF, FKK, CH, AML), diagnosis of patient (all authors), histological examinations (AML, CH), morphometry (JH, $\mathrm{MH}, \mathrm{SvK}$ ), genetics (IW, MZ), further contributions and final approval of manuscript (all Authors).

\section{Acknowledgements}

This research did not receive any specific grant from funding agencies in the public, commercial, or not-for-profit sectors. The authors would like to thank the patient who explicitly allowed the first author to publish the case report. The authors would like to thank A. Meyer for photographic documentation of surgical treatment.

\section{References}

1 Solomon LM and Esterly NB: Epidermal and other congenital organoid nevi. Curr Probl Pediatr 6(1): 1-56, 1975. PMID: 173496. DOI: 10.1016/s0045-9380(75)80010-7

2 Castilla EE, da Graça Dutra $M$ and Orioli-Parreiras IM: Epidemiology of congenital pigmented naevi: I. Incidence rates and relative frequencies. Br J Dermatol 104(3): 307-315, 1981. PMID: 7213564. DOI: 10.1111/j.1365-2133.1981.tb00954.x

3 Flores-Sarnat L: Epidermal nevus syndrome: In: Dulac O, Lassonde M and Sarnat HB (eds.): Handbook on Clinical Neurology, Vol. III ( $3^{\text {rd }}$ series), Pediatric Neurology, Part I. Amsterdam, Elsevier, pp. 349-368, 2013.

4 Ruggieri $\mathrm{M}$ and Praticò $\mathrm{AD}$ : Mosaic neurocutaneous disorders and their causes. Semin Pediatr Neurol 22(4): 207-233, 2015. PMID: 26706010. DOI: 10.1016/j.spen.2015.11.001

5 Asch S and Sugarman JL: Epidermal nevus syndromes. Handb Clin Neurol 132: 291-316, 2015. PMID: 26564089. DOI: 10.1016/B978-0-444-62702-5.00022-6

6 Happle R: Mosaicism in human skin. Understanding the patterns and mechanisms. Arch Dermatol 129(11): 1460-1470, 1993. PMID: 8239703.

7 Su WP: Histopathologic varieties of epidermal nevus. A study of 160 cases. Am J Dermatopathol 4(2): 161-170, 1982. PMID: 7048967. DOI: 10.1097/00000372-198204000-00011

8 Happle R: The group of epidermal nevus syndromes Part I. Well defined phenotypes. J Am Acad Dermatol 63(1): 1-22; quiz 234, 2010. PMID: 20542174. DOI: 10.1016/j.jaad.2010.01.017

9 Happle R: Epidermal nevus syndromes. Semin Dermatol 14(2): 111-121, 1995. PMID: 7640190. DOI: 10.1016/s 10855629(05)80006-9

10 Happle R: How many epidermal nevus syndromes exist? A clinicogenetic classification. J Am Acad Dermatol 25(3): 550-556, 1991. PMID: 1918493. DOI: 10.1016/0190-9622(91)70238-w

11 Rogers M, McCrossin I and Commens C: Epidermal nevi and the epidermal nevus syndrome. A review of 131 cases. J Am Acad Dermatol 20(3): 476-488, 1989. PMID: 2918116. DOI: 10.1016/s0190-9622(89)70061-x

12 Ruggieri $M$ and Pascual-Castroviejo I: SchimmelpenningFeuerstein-Mims syndrome (Nevus sebaceous Syndrome). In: Ruggieri M, Pascual-Castroviejo I and Di Rocco C (eds.): Neurocutaneous Disorders, Phakomatoses and Hamartoneoplastic Syndromes. Wien-New York, Springer-Verlag, pp. 559-573, 2008.

13 Diven DG, Solomon AR, McNeely MC and Font RL: Nevus sebaceus associated with major ophthalmologic abnormalities. Arch Dermatol 123(3): 383-386, 1987. PMID: 3101614. 
14 Groesser L, Herschberger E, Ruetten A, Ruivenkamp C, Lopriore E, Zutt M, Langmann T, Singer S, Klingseisen L, Schneider-Brachert W, Toll A, Real FX, Landthaler M and Hafner C: Postzygotic HRAS and KRAS mutations cause nevus sebaceous and Schimmelpenning syndrome. Nat Genet 44(7): 783-787, 2012. PMID: 22683711. DOI: 10.1038/ng.2316

15 Levinsohn JL, Tian LC, Boyden LM, McNiff JM, Narayan D, Loring ES, Yun D, Sugarman JL, Overton JD, Mane SM, Lifton RP, Paller AS, Wagner AM, Antaya RJ and Choate KA: Wholeexome sequencing reveals somatic mutations in HRAS and KRAS, which cause nevus sebaceus. J Invest Dermatol 133(3): 827-830, 2013. PMID: 23096712. DOI: 10.1038/jid.2012.379

16 Sun BK, Saggini A, Sarin KY, Kim J, Benjamin L, LeBoit PE and Khavari PA: Mosaic activating RAS mutations in nevus sebaceus and nevus sebaceus syndrome. J Invest Dermatol 133(3): 824-827, 2013. PMID: 23096709. DOI: 10.1038/jid.2012.377

17 Aslam A, Salam A, Griffiths CE and McGrath JA: Naevus sebaceus: a mosaic RASopathy. Clin Exp Dermatol 39(1): 1-6, 2014. PMID: 24341474. DOI: 10.1111/ced.12209

18 Mitchell BJ, Rogers GF and Wood BC: A patient with Schimmelpenning syndrome and mosaic KRAS mutation. J Craniofac Surg 30(1): 184-185, 2019. PMID: 30394973. DOI: $10.1097 /$ SCS.0000000000004887

19 Happle R: Nevus sebaceus is a mosaic RASopathy. J Invest Dermatol 133(3): 597-600, 2013. PMID: 23399824. DOI: 10.1038/jid.2012.447

20 Lihua J, Feng G, Shanshan M, Jialu X and Kewen J: Somatic KRAS mutation in an infant with linear nevus sebaceous syndrome associated with lymphatic malformations: A case report and literature review. Medicine (Baltimore) 96(47): e8016, 2017. PMID: 29381910. DOI: 10.1097/MD. 0000000000008016

21 Farschtschi S, Mautner VF, Hollants S, Hagel C, Spaepen M, Schulte C, Legius E and Brems H: Keratinocytic epidermal nevus syndrome with Schwann cell proliferation, lipomatous tumour and mosaic KRAS mutation. BMC Med Genet 16: 6, 2015. PMID: 25928347. DOI: 10.1186/s12881-015-0146-5

22 Luo S and Tsao H: Epidermal, sebaceous, and melanocytic nevoid proliferations are spectrums of mosaic RASopathies. J Invest Dermatol 134(10): 2493-2496, 2014. PMID: 25219651. DOI: $10.1038 /$ jid.2014.244

23 Happle R: Spuren der Frühzeit: embryologische Verteilungsmuster bei Hauterkrankungen. Fortschritte der praktischen Dermatologie und Venerologie: 128-136, 2019. DOI: 10.1007/978-3-642-56437-6_19

24 Happle R: Lethal genes surviving by mosaicism: a possible explanation for sporadic birth defects involving the skin. J Am Acad Dermatol 16(4): 899-906, 1987. PMID: 3033033. DOI: 10.1016/s0190-9622(87)80249-9

25 El Ezzi O, de Buys Roessingh AS, Bigorre M and Captier G: Syndromic sebaceous nevus: current findings. Int J Dermatol 57(5): 599-604, 2018. PMID: 29453776. DOI: 10.1111/ijd.13942

26 Kelley JE, Hibbard ED and Giansanti JS: Epidermal nevus syndrome. Report of a case with unusual oral manifestations. Oral Surg Oral Med Oral Pathol 34(5): 774-780, 1972. PMID: 4507445. DOI: 10.1016/0030-4220(72)90295-2

27 Kaplan I, Metzker A and Calderon S: Epidermal nevus syndrome with maxillary involvement. Int J Oral Maxillofac Surg 22(5): 298-300, 1993. PMID: 8245571. DOI: 10.1016/s09015027(05)80520-x
28 Blaschko A: Die Nervenverteilung in der Haut in ihrer Beziehung zu den Erkrankungen der Haut. Beilage zu den Verhandlungen der Deutschen Dermatologischen Gesellschaft, VII Congress, Breslau, 1901. Wien \& Leipzig, Braumüller, 1901.

29 Schimmelpenning GW: [Clinical contribution to symptomatology of phacomatosis]. Fortschr Geb Rontgenstr Nuklearmed 87(6): 716-720, 1957. PMID: 13512450.

30 Feuerstein RC and Mims LC: Linear nevus sebaceus with convulsions and mental retardation. Am J Dis Child 104: 675679, 1962. PMID: 13944982. DOI: 10.1001/archpedi.1962. 02080030675013

31 Greene AK, Rogers GF and Mulliken JB: Schimmelpenning syndrome: an association with vascular anomalies. Cleft Palate Craniofac J 44(2): 208-215, 2007. PMID: 17328648. DOI: 10.1597/06-025.1

32 Hornstein OP and Knickenberg M: [On the SchimmelpenningFeuerstein-Mims-syndrome (Organoid Nevus-Phakomatosis) (author's transl)]. Arch Dermatol Forsch 250(1): 35-50, 1974. PMID: 4211536.

33 Hornstein OP: Erkrankungen des Mundes. Berlin - Köln, Kohlhammer, pp. 84-87, 1996.

34 Krause MH, Ulrich J and Gollnick H: [Systematic sebaceous nevus with multiple secondary tumors as the chief symptom of Schimmelpenning-Feuerstein-Mims syndrome]. Hautarzt 52(4): 339-343, 2001. PMID: 11382127. DOI: 10.1007/s001050051319

35 Lovejoy FH Jr and Boyle WE Jr: Linear nevus sebaceous syndrome: report of two cases and a review of the literature. Pediatrics 52(3): 382-387, 1973. PMID: 4730395.

36 Fahnenstich H, Biltz $\mathrm{H}$ and Kreysel HW: [Organoid nevus syndrome (Schimmelpenning-Feuerstein-Mims syndrome): case report and literature]. Klin Padiatr 201(1): 54-57, 1989. PMID: 2649738. DOI: $10.1055 / \mathrm{s}-2007-1025275$

37 Adams D, Athalye L, Schwimer C and Bender B: A profound case of linear epidermal nevus in a patient with epidermal nevus syndrome. J Dermatol Case Rep 5(2): 30-33, 2011. PMID: 21894253. DOI: $10.3315 /$ jdcr.2011.1069

38 Rijntjes-Jacobs EG, Lopriore E, Steggerda SJ, Kant SG and Walther FJ: Discordance for Schimmelpenning-Feuerstein-Mims syndrome in monochorionic twins supports the concept of a postzygotic mutation. Am J Med Genet A 152A(11): 2816-2819, 2010. PMID: 20949522. DOI: 10.1002/ajmg.a.33635

39 Bitter K: [Congenital nevus sebaceous in the trigeminal nerve region with brain abnormalities and giant cell tumors of the jaws]. Dtsch Zahn Mund Kieferheilkd Zentralbl Gesamte 56(1): 17-24, 1971. PMID: 4993887.

40 Dwiyana RF, Hazari MN, Diana IA, Gondokaryono SP, Effendi RMRA and Gunawan H: Schimmelpenning syndrome with large nevus sebaceous and multiple epidermal nevi. Case Rep Dermatol 12(3): 186-191, 2020. PMID: 33250735. DOI: 10.1159/000509992

41 Joshi A, Agrawal S, Singh K, Sah SP, Agarwalla A, Thakur SKD and Rauniar RK: Schimmelpenning syndrome (Epidermal Nevus Syndrome): A case report. The Gulf J Dermatol Venereol 19: 6167, 2012.

42 Grebe TA, Rimsza ME, Richter SF, Hansen RC and Hoyme HE: Further delineation of the epidermal nevus syndrome: two cases with new findings and literature review. Am J Med Genet 47(1): 24-30, 1993. PMID: 8368247. DOI: 10.1002/ajmg.1320470106

43 Nagatsuma M, Takasawa K, Yamauchi T, Nakagawa R, Mizuno T, Tanaka E, Yamamoto K, Uemura N, Kashimada K and Morio T: A postzygotic KRAS mutation in a patient with Schimmelpenning 
syndrome presenting with lipomatosis, renovascular hypertension, and diabetes mellitus. J Hum Genet 64(2): 177-181, 2019. PMID: 30443000. DOI: 10.1038/s10038-018-0539-3

$44 \mathrm{Nel} \mathrm{C}$, Uys A, Robinson L and van Heerden WFP: Multiple adenomatoid odontogenic tumours associated with eight impacted teeth. Oral Radiol 37(2): 321-327, 2021. PMID: 32770291. DOI: 10.1007/s11282-020-00471-w

45 Bazopoulou-Kyrkanidou E, Alexandridis C, Tosios KI, Sotiriadou S and Angelopoulos AP: Epidermal nevus syndrome with development of a mandibular ameloblastoma. Oral Surg Oral Med Oral Pathol Oral Radiol Endod 90(1): 64-70, 2000. PMID: 10884637. DOI: 10.1067/moe.2000.106301

46 Brown HM and Gorlin RJ: Oral mucosal involvement in nevus unius lateris (ichthyosis hystrix). Arch Dermatol 81: 509-515, 1960. PMID: 13804942. DOI: 10.1001/archderm.1960.03730040013003

47 Chacon-Camacho OF, Lopez-Moreno D, Morales-Sanchez MA, Hofmann E, Pacheco-Quito M, Wieland I, Cortes-Gonzalez V, Villanueva-Mendoza C, Zenker M and Zenteno JC: Expansion of the phenotypic spectrum and description of molecular findings in a cohort of patients with oculocutaneous mosaic RASopathies. Mol Genet Genomic Med 7(5): e625, 2019. PMID: 30891959. DOI: $10.1002 / \mathrm{mgg} 3.625$

48 Asch S and Sugarman JL: Fifty-two words for snow: dermatologists naming epidermal naevi. Br J Dermatol 178(1): 296, 2018. PMID: 28960256. DOI: 10.1111/bjd.16012

49 Jones EW and Heyl T: Naevus sebaceus. A report of 140 cases with special regard to the development of secondary malignant tumours. Br J Dermatol 82(2): 99-117, 1970. PMID: 5435080. DOI: $10.1111 / j .1365-2133.1970 . t b 15000 . x$

50 Harth W and Linse R: Schimmelpenning-Feuerstein-MimsSyndrom in Kombination mit einem primären Lymphödem und Basalzellkarzinomen. Akt Dermatol 27: 66-69, 2001. DOI: 10.1055/s-2001-11487

51 Rosen H, Schmidt B, Lam HP, Meara JG and Labow BI: Management of nevus sebaceous and the risk of Basal cell carcinoma: an 18-year review. Pediatr Dermatol 26(6): 676-681, 2009. PMID: 19686305. DOI: 10.1111/j.1525-1470.2009.00939.x

52 Patel P, Malik K and Khachemoune A: Sebaceus and Becker's nevus: Overview of their presentation, pathogenesis, associations, and treatment. Am J Clin Dermatol 16(3): 197-204, 2015. PMID: 25782676. DOI: 10.1007/s40257-015-0123-y

53 Happle R and Assim A: The lines of Blaschko on the head and neck. J Am Acad Dermatol 44(4): 612-615, 2001. PMID: 11260527. DOI: $10.1067 / \mathrm{mjd} .2001 .112386$

54 Haberland-Carrodeguas C, Allen CM, Lovas JG, Hicks J, Flaitz $\mathrm{CM}$, Carlos R and Stal S: Review of linear epidermal nevus with oral mucosal involvement-series of five new cases. Oral Dis 14(2): 131-137, 2008. PMID: 18302672. DOI: 10.1111/j.16010825.2006.01355.x

55 Santos MD, Duarte AS, Carvalho GM, Guimarães AC, Zappelini CE, Coelho Dal Rio AC, Corrêa ME, Milani Altemani AM and Danielli Nicola EM: Linear epidermal nevus of the oral cavity: a rare diagnosis. Case Rep Med 2012: 206836, 2012. PMID: 22811716. DOI: $10.1155 / 2012 / 206836$

56 Baliga V, Gopinath VP, Baliga S and Chandra U: Oral findings in a patient with Sebaceous Nevi - A Case Report. J Int Oral Health 5(5): 139-142, 2013. PMID: 24324318.

57 Reichart PA, Lubach D and Becker J: Gingival manifestation in linear nevus sebaceous syndrome. Int J Oral Surg 12(6): 437-443, 1983. PMID: 6425234. DOI: 10.1016/s0300-9785(83)80035-0
58 Fritzsch C, König R and Jacobi G: [SchimmelpenningFeuerstein-Mims syndrome and its neurologic manifestations. 6 personal cases and review of the literature]. Klin Padiatr 207(5): 288-297, 1995. PMID: 7500606. DOI: 10.1055/s-2008-1046554

59 Murakami A, Skovby F, Andreasen JO, Cohen MM Jr, Jensen BL and Kreiborg S: Oral manifestations of Schimmelpenning syndrome: case report and review of literature. Ann Acad Med Singap 28(5): 744-748, 1999. PMID: 10597363.

60 Warnke PH, Schimmelpenning GW, Happle R, Springer IN, Hauschild A, Wiltfang J, Acil Y, Sherry E, Proksch E, Luettges $\mathrm{J}$ and Russo PA: Intraoral lesions associated with sebaceous nevus syndrome. J Cutan Pathol 33(2): 175-180, 2006. PMID: 16420315. DOI: 10.1111/j.0303-6987.2006.00374.x

61 Warnke PH, Russo PA, Schimmelpenning GW, Happle R, Härle F, Hauschild A, Sherry E, Luttges J, Terheyden H, Dunsche A and Springer IN: Linear intraoral lesions in the sebaceous nevus syndrome. J Am Acad Dermatol 52(2 Suppl 1): 62-64, 2005. PMID: 15692521. DOI: 10.1016/j.jaad.2004.05.046

62 Warnke PH, Hauschild A, Schimmelpenning GW, Terheyden H, Sherry E and Springer IN: The sebaceous nevus as part of the Schimmelpenning-Feuerstein-Mims Syndrome-an obvious phacomatosis first documented in 1927. J Cutan Pathol 30(7): 470-472, 2003. PMID: 12859747. DOI: 10.1034/j.16000560.2003.00091.x

63 Ernst LM, Quinn PD and Alawi F: Novel oral findings in Schimmelpenning syndrome. Am J Med Genet A 143A(8): 881883, 2007. PMID: 17366580. DOI: 10.1002/ajmg.a.31663

64 Chaves RRM, Júnior AACP, Gomes CC, de Castro WH and Gomez RS: Multiple adenomatoid odontogenic tumors in a patient with Schimmelpenning syndrome. Oral Surg Oral Med Oral Pathol Oral Radiol 129(1): e12-e17, 2020. PMID: 31402313. DOI: 10.1016/j.oooo.2019.06.006

65 Slootweg PJ and Meuwissen PR: Regional odontodysplasia in epidermal nevus syndrome. J Oral Pathol 14(3): 256-262, 1985. PMID: 3921681. DOI: 10.1111/j.1600-0714.1985.tb00489.x

66 Baliga V, Gopinath VP, Baliga S, Ramachandra SS, Jithendra KD and Shetty S: Intraoral manifestations in a patient with Epidermal nevus syndrome. J Contemp Dent Pract 14(4): 762-765, 2013. PMID: 24309363. DOI: 10.5005/jp-journals-10024-1399

67 Baghaei-Rad M, Doku HC and Ficarelli J: Epidermal nevus syndrome with maxillary involvement. J Oral Maxillofac Surg 40(12): 821-823, 1982. PMID: 6958846. DOI: 10.1016/02782391(82)90183-5

68 Colletti G, Allevi F, Moneghini L, Rabbiosi D, Bertossi D, Frau I, Biglioli F and Tadini G: Epidermal nevus and ameloblastoma: a rare association. Oral Surg Oral Med Oral Pathol Oral Radiol 117(3): e275-e279, 2014. PMID: 23969333. DOI: 10.1016/ j.000o.2013.06.003

69 Sakkas N, Schramm A, Gellrich NC, Gutwald R, Düker J and Schmelzeisen R: The ameloblastic fibroodontoma of the maxilla: case report of a child with Schimmelpenning-Feuerstein-Mims syndrome/skin-eye-brain-heart syndrome. J Oral Maxillofac Surg 64(3): 524-527, 2006. PMID: 16487818. DOI: 10.1016/j.joms. 2005.11.005

70 Steigleder GK and Cortes AC: Verhalten der Talgdrüsen im Talgdrüsennävus während des Kindesalters. Arch Klin Exp Dermatol 239: 323-328, 1971.

71 Morency R and Labelle H: Nevus sebaceus of Jadassohn: a rare oral presentation. Oral Surg Oral Med Oral Pathol 64(4): 460-462, 1987. PMID: 3477768. DOI: 10.1016/0030-4220(87)90153-8 
72 Hickman RE, Eveson JW and Cawson RA: Nevus unius lateris and intraoral verrucous nevi. Oral Surg Oral Med Oral Pathol 66(2): 226-229, 1988. PMID: 3174057. DOI: 10.1016/00304220(88)90098-9

73 Klein GL, Dallas JS, Hawkins HK, Swischuk LE and McCauley RL: Congenital linear sebaceous nevus syndrome. J Bone Miner Res 13(6): 1056-1057, 1998. PMID: 9626639. DOI: 10.1359/ jbmr.1998.13.6.1056

74 Amato C, Elia M and Schepis C: Schimmelpenning syndrome: a kind of craniofacial epidermal nevus associated with cerebral and ocular MR imaging abnormalities. AJNR Am J Neuroradiol 31(5): E47-E48, 2010. PMID: 20299435. DOI: 10.3174/ ajnr.A2062

75 Thesleff I and Juuri E: Tooth development. In: McCauley LK and Somerman MJ (eds). Mineralized Tissues in Oral and Craniofacial Science: Biological Principles and Clinical Correlations. $1^{\text {st }}$ edition, Ames (Iowa), Wiley and Sons, pp. 119127, 2012.

76 Rott HD: Extracutaneous analogies of Blaschko lines. Am J Med Genet 85(4): 338-341, 1999. PMID: 10398255. DOI: 10.1002/ (sici)1096-8628(19990806)85:4<338::aid-ajmg5>3.0.co;2-8

77 Ludwig K and Tenconi R: A case of diploid/triploid mosaicism with dental Blaschko lines. Clin Dysmorphol 18(4): 232-233, 2009. PMID: 19625954. DOI: 10.1097/MCD.0b013e32832dc3aa

78 Gysin S and Itin P: Blaschko linear enamel defects - A marker for focal dermal hypoplasia: Case report of focal dermal hypoplasia. Case Rep Dermatol 7(2): 90-94, 2015. PMID: 26078738. DOI: $10.1159 / 000430781$

79 Heike CL, Cunningham ML, Steiner RD, Wenkert D, Hornung RL, Gruss JS, Gannon FH, McAlister WH, Mumm S and Whyte MP: Skeletal changes in epidermal nevus syndrome: does focal bone disease harbor clues concerning pathogenesis? Am J Med Genet A 139A(2): 67-77, 2005. PMID: 16222671. DOI: 10.1002/ajmg.a.30915

80 Solomon LM, Fretzin DF and Dewald RL: The epidermal nevus syndrome. Arch Dermatol 97(3): 273-285, 1968. PMID: 5641330 .
$81 \mathrm{Kim}$ J, Zambrano EV and McNiff JM: Congenital panfollicular nevus associated with polydactyly. J Cutan Pathol 34 Suppl 1: 14-17, 2007. PMID: 17997731. DOI: 10.1111/j.16000560.2006.00714.x

82 Kaliyadan F, Nampoothiri S, Sunitha V and Kuruvilla VE: Nevus comedonicus syndrome-nevus comedonicus associated with ipsilateral polysyndactyly and bilateral oligodontia. Pediatr Dermatol 27(4): 377-379, 2010. PMID: 20653857. DOI: 10.1111/j.1525-1470.2010.01170.x

83 Biesecker LG: Polydactyly: how many disorders and how many genes? Am J Med Genet 112(3): 279-283, 2002. PMID: 12357471. DOI: 10.1002/ajmg.10779

84 Kuroda Y, Ohashi I, Enomoto Y, Naruto T, Baba N, Tanaka Y, Aida N, Okamoto N, Niihori T, Aoki Y and Kurosawa K: A postzygotic NRAS mutation in a patient with Schimmelpenning syndrome. Am J Med Genet A 167A(9): 2223-2225, 2015. PMID: 25914220. DOI: 10.1002/ajmg.a.37135

85 Kim D, Benjamin LT, Sahoo MK, Kim J and Pinsky BA: Human papilloma virus is not prevalent in nevus sebaceus. Pediatr Dermatol 31(3): 326-330, 2014. PMID: 24224641. DOI: $10.1111 /$ pde. 12249

86 Carlson JA, Cribier B, Nuovo $G$ and Rohwedder A: Epidermodysplasia verruciformis-associated and genital-mucosal high-risk human papillomavirus DNA are prevalent in nevus sebaceus of Jadassohn. J Am Acad Dermatol 59(2): 279-294, 2008. PMID: 18638629. DOI: 10.1016/j.jaad.2008.03.020

87 Kansky AA, Seme K, Maver PJ, Luzar B, Gale N and Poljak M: Human papillomaviruses (HPV) in tissue specimens of oral squamous cell papillomas and normal oral mucosa. Anticancer Res 26(4B): 3197-3201, 2006. PMID: 16886657.

Received August 19, 2021

Revised September 1, 2021

Accepted September 29, 2021 